Review Article

\title{
Therapeutic Applications of Cannabinoids in Cardiomyopathy and Heart Failure
}

\author{
J. A. Garza-Cervantes $\mathbb{D}^{1},{ }^{1}$ M. Ramos-González $\mathbb{D},{ }^{1}$ O. Lozano $\mathbb{D},{ }^{1,2}$ C. Jerjes-Sánchez $\mathbb{D},{ }^{2}$ \\ and G. García-Rivas iD ${ }^{1,2,3}$ \\ ${ }^{1}$ Tecnologico de Monterrey, Escuela de Medicina y Ciencias de la Salud, Cátedra de Cardiología y Medicina Vascular, Monterrey, \\ Nuevo León, Mexico \\ ${ }^{2}$ Tecnologico de Monterrey, Hospital Zambrano Hellion, TecSalud, Centro de Investigación Biomédica. San Pedro Garza García, \\ Nuevo León, Mexico \\ ${ }^{3}$ Tecnologico de Monterrey, Hospital Zambrano Hellion, TecSalud, Centro de Medicina Funcional, San Pedro Garza García, \\ Nuevo León, Mexico
}

Correspondence should be addressed to G. García-Rivas; gdejesus@itesm.mx

Received 25 July 2020; Revised 21 September 2020; Accepted 23 September 2020; Published 27 October 2020

Academic Editor: Marcos R. de Oliveira

Copyright (C) 2020 J. A. Garza-Cervantes et al. This is an open access article distributed under the Creative Commons Attribution License, which permits unrestricted use, distribution, and reproduction in any medium, provided the original work is properly cited.

\begin{abstract}
A large number of cannabinoids have been discovered that could play a role in mitigating cardiac affections. However, none of them has been as widely studied as cannabidiol (CBD), most likely because, individually, the others offer only partial effects or can activate potential harmful pathways. In this regard, CBD has proven to be of great value as a cardioprotective agent since it is a potent antioxidant and anti-inflammatory molecule. Thus, we conducted a review to condensate the currently available knowledge on $\mathrm{CBD}$ as a therapy for different experimental models of cardiomyopathies and heart failure to detect the molecular pathways involved in cardiac protection. CBD therapy can greatly limit the production of oxygen/nitrogen reactive species, thereby limiting cellular damage, protecting mitochondria, avoiding caspase activation, and regulating ionic homeostasis. Hence, it can affect myocardial contraction by restricting the activation of inflammatory pathways and cytokine secretion, lowering tissular infiltration by immune cells, and reducing the area of infarct and fibrosis formation. These effects are mediated by the activation or inhibition of different receptors and target molecules of the endocannabinoid system. In the final part of this review, we explore the current state of CBD in clinical trials as a treatment for cardiovascular diseases and provide evidence of its potential benefits in humans.
\end{abstract}

\section{Introduction}

Cannabidiol (CBD) is one of the 113 identified phytocannabinoids found in Cannabis sativa. It is nonpsychotropic and constitutes up to $40 \%$ of the plant extract [1]. It can also be obtained synthetically. The molecular structure of CBD, and other cannabinoids, is shown in Figure 1. Since the identification of the cannabinoid receptor in the rat brain [2], there has been increasing interest among researchers in the use of cannabinoids to treat diseases. Of particular interest has been CBD, which, in addition to its lack of psychotropic activity, is a potent anti-inflammatory molecules, and reduces the production of reactive oxygen and nitrogen species (ROS/RNS), thus resulting in reduced tissue injury $[3,4]$. Such effects can be taken advantage of in varied diseases, such as cardiovascular and neurodegenerative diseases, cancer, pain, obesity, and metabolic syndrome. For this range of applications, it is worth noting that $\mathrm{CBD}$ is only approved in 27 countries to treat multiple sclerosis. In the United States (US), the Food and Drug Administration (FDA) has approved its use in the treatment of Dravet and Lennox-Gastaut syndromes [5]. Even if it has been shown that $\mathrm{CBD}$ has effects on cannabinoid type 2 receptors (CB2s) in the brain [6] but not cannabinoid type 1 receptors $(\mathrm{CB} 1 \mathrm{~s})$, there is still controversy regarding the specific pathways involved in its anti-inflammatory properties. 
<smiles>CCCCC/C=C\C/C=C\C/C=C\C/C=C\CCCC(=O)OC(CO)CO</smiles>

(a)<smiles>C=C(C)[C@H]1CCC(C)=C[C@H]1c1c(O)cc(CCCCC)cc1O</smiles>

(c)<smiles>Cc1c(C(=O)NN2CCCCC2)nn(-c2ccc(Cl)cc2Cl)c1-c1ccc(Cl)cc1</smiles>

(e)

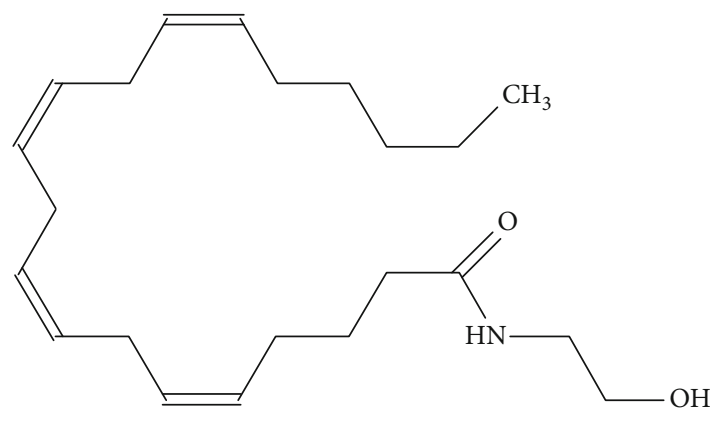

(b) (d)

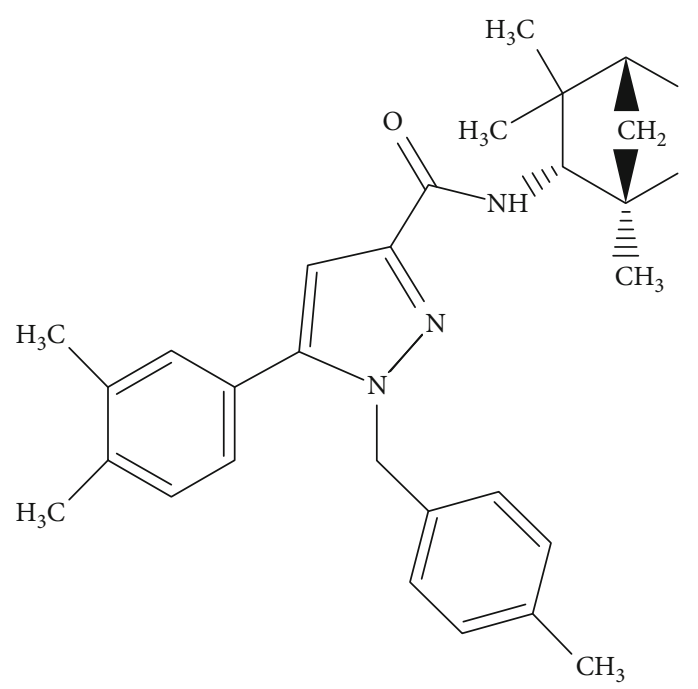

(f)

Figure 1: Molecular structure of cannabinoids of cardiovascular interest. (a) 2-arachidonoylglycerol, (b) anandamide, (c) CBD, (d) palmitoylethanolamide, (e) SR141716A, and (f) SR144528.

Regarding the very production of $\mathrm{CBD}$, the synthetic route is preferred over extracts for several reasons, including high composition purity, pesticide removal, consistent quality control between batches, and ease of scalability without using Cannabis sativa as the initial source. Moreover, some synthetics, such as 8,9-dihydrocannibidiol 
(H2CBD), do not activate the THC pathway, unlike CBD extracts $[7,8]$.

Cardiovascular diseases (CVDs) are the leading cause of mortality worldwide [9]. They have a set of characteristic molecular components, such as a proinflammatory profile present in heart failure (HF) [10], diabetic cardiomyopathy [11], and autoimmune myocarditis [5]. In addition, alterations to oxidative phosphorylation and mitochondrial reactive oxygen species (ROS) are linked to hypoxia [12] and ischemia/reperfusion injury $[13,14]$, where excess ROS and alterations to the renin-angiotensin-aldosterone system are linked to hypertension $[15,16]$. Similarly, the handling of intracellular $\mathrm{Ca}^{2+}$ is paramount in $\mathrm{HF}$ as well as arrhythmias [17]. All these molecular components, associated with diverse CVDs, can be modulated with CBD administration. The objective of this study is to review the current evidence related to $\mathrm{CBD}$ and other nonpsychoactive cannabinoids, including their use in CVDs, especially HF and cardiomyopathies. From this evidence, we finalize with a proposed roadmap of the pathways of CBD's effects on CVDs.

\section{Cardiovascular Effects of CBD}

2.1. CBD as a Therapeutic Approach in Models of Cardiopathy. Many authors have studied the cardiovascular effects of CBD to explore its therapeutic potential in a variety of cardiomyopathies, from healing injury caused by several cell stressors to decreasing the incidence of cardiac damage. These effects are reported using different models: cells, tissues, and animals. Table 1 summarizes the use of CBD in cardiomyopathies.

2.2. Cardiovascular Effects of CBD Observed In Vitro. The alteration of cardiovascular cells could compromise heart function, and vascular diseases are linked to proliferative and inflammatory responses. For example, Schwartz et al. [18] demonstrated that CBD inhibits the growth factormediated proliferation and migration of vascular smooth muscle cells (VSMC). Stanley et al. [19] characterized CBDinduced intracellular signaling using human aortic endothelial cells (HAECs), increasing vasorelaxation, and a decrease of proinflammatory proteins. Using HCAECs (coronary artery endothelial cells), Rajesh et al. [20] found that CBD attenuates the inflammatory response caused by high glucose concentrations in endothelial cells. Furthermore, CBD caused a reduction in oxidative and nitrosative stress in an in vitro study using primary human cardiomyocytes [11] by decreasing reactive oxygen/nitrogen species and NF- $\kappa \beta$ expression. Similarly, using Chinese hamster ovary $(\mathrm{CHO})$ cells transfected with a human $\mathrm{Na}_{\mathrm{v}} 1.5 \alpha$-subunit and then submitted to high glucose conditions, Fouda et al. [21] found that CBD mitigated the elevation of ROS and increased the length of action potential provoked by these conditions, suggesting that the antioxidant property of $\mathrm{CBD}$, in conjunction with a sodium channel inhibitor, may have cardioprotective effects against arrhythmia and cytotoxicity caused by high glucose environments.

Ali et al. [22] observed the effects of CBD on the contractility and electrophysiological properties of rat ventricular myocytes. The results indicate that the inhibition of $\mathrm{Ca}^{2+}$ signaling underlies the negative inotropic effects of $\mathrm{CBD}$ in myocytes, presenting a reduction in maximal shortening amplitudes with no alteration of the time course of contraction. However, Robertson-Gray et al. [23] observed a cardioprotective effect of CBD against l- $\alpha$-lysophosphatidylinositol (LPI), an endogenous ligand of $G$ protein-coupled receptor 55 (GPR55), a putative cannabinoid receptor, which is also elevated in patients with the coronary syndrome. The injury was decreased by CBD acting as an antagonist of the GPR55 receptor. A similar effect of GPR55 antagonism was observed by Marichal-Cancino et al. [24], as CBD blocked the LPIinduced inhibition of vasopressor responses produced by noradrenaline, suggesting this receptor may play a role in CBD's effects.

2.3. Cardiovascular Effects of CBD Observed Ex Vivo. During an ex vivo experiment performed by Stanley et al. [25], improved myocardial function was observed due to CBDenhanced acetylcholine-induced vasorelaxation in Zucker diabetic rat aorta. Similarly, Wheal et al. [26] reported the improvement of endothelium-dependent vasorelaxation in mesenteric arteries ex vivo in diabetic rats. After seven days of treatment with $\mathrm{CBD}$, vasorelaxation was mediated by $\mathrm{COX}$ and NO mechanisms, given that indomethacin or LNAME inhibited the effect. Furthermore, these vasorelaxant effects observed in diabetic rats were not observed in the control groups, suggesting that CBD reveals its positive effect when vascular dysfunction is present. In a study conducted by Stanley et al. [19], CBD caused significant vasorelaxation of precontracted human mesenteric arteries compared in the control group, and the effect was significantly reduced by the endothelium removal and the use of a high potassium physiological salt solution. The use of AM251 and LY320135, $\mathrm{CB}_{1}$ receptor antagonists, and the transient receptor potential cation channel (TRP) desensitizer capsaicin abolished the vasorelaxation effect of CBD. Meanwhile, O'Sullivan et al. [27] studied the functional vascular effect of CBD in rat aortae. CBD caused vasorelaxation of the precontracted aorta in a time-dependent manner. In contrast, in this study, pretreatment with AM251, AM630, or capsaicin did not affect the vascular response to $\mathrm{CBD}$, suggesting neither $\mathrm{CB}_{1}, \mathrm{CB}_{2}$ receptors, nor TRP in aorta, respectively, was involved.

\subsection{Cardiovascular Effects of CBD Observed In Vivo}

2.4.1. Use of CBD on Hypertension Models. Cannabinoids are known to reduce oxidative metabolism in different tissues, including the heart [28]. Using a primary and secondary hypertension rat model, Remiszewski et al. [29] found a reduction in oxidative stress in both the heart and plasma when rats were treated with CBD but, unexpectedly, did not modify the blood pressure (BP) or heart rate (HR). In another hypertensive model, Kossakowski et al. [30] observed the cardiovascular effect of CBD on conscious and anesthetized, spontaneously hypertensive rats. The intravenous (i.v.) administration of CBD to anesthetized rats caused a dose-dependent decrease in HR, as well as systolic and diastolic blood pressure, more markedly in hypertensive rats 
TABLE 1: Effect of CBD in different cardiomyopathy experimental models.

\begin{tabular}{|c|c|c|c|c|}
\hline Biological subject & $\begin{array}{c}\mathrm{CBD} \\
\text { concentration }\end{array}$ & Experimental model & $\mathrm{CBD}$ treatment key results & Ref \\
\hline \multicolumn{5}{|l|}{ In vitro models } \\
\hline $\begin{array}{l}\text { Human umbilical } \\
\text { artery smooth } \\
\text { muscle cells }\end{array}$ & $0.1-10 \mu \mathrm{M}$ & ROS modulation with NAC & $\begin{array}{l}\text { Protective effect against aberrant proliferation and } \\
\text { migration by an increased expression of HO-1 }\end{array}$ & {$[18]$} \\
\hline $\begin{array}{l}\text { Human aortic } \\
\text { endothelial cells }\end{array}$ & $10 \mu \mathrm{M}$ & High glucose/insulin & $\begin{array}{l}\text { Decreased inflammatory }(\downarrow N F-\kappa \beta,) \text { proliferation }(\downarrow J N K \text {, } \\
\downarrow \text { p70s6K), and increased survival ( } \uparrow \text { Akt) pathways }\end{array}$ & {$[19]$} \\
\hline $\begin{array}{l}\text { Human coronary } \\
\text { artery endothelial } \\
\text { cells }\end{array}$ & $\begin{array}{l}1.5,3,4.5 \\
\quad 6 \mu \mathrm{M}\end{array}$ & $\begin{array}{l}\text { High glucose-induced } \\
\text { endothelial cell inflammatory } \\
\text { response }\end{array}$ & $\begin{array}{l}\text { Reduced mitochondrial superoxide generation, NF- } \kappa \beta \\
\text { activation, and ICAM-1 and VCAM- } 1 \text { expression }\end{array}$ & {$[20]$} \\
\hline $\begin{array}{l}\text { Primary human } \\
\text { cardiomyocytes }\end{array}$ & $4 \mu \mathrm{M}$ & $\begin{array}{l}\text { Diabetic cardiomyopathy by } \\
\text { high glucose culture }\end{array}$ & $\begin{array}{c}\text { Decrease of oxidative/nitrosative stress and NF- } \kappa \beta \\
\text { activation }\end{array}$ & {$[11]$} \\
\hline $\begin{array}{l}\text { Rat ventricular } \\
\text { myocytes }\end{array}$ & $1-10 \mu \mathrm{M}$ & Normal conditions & Inhibition of L-type $\mathrm{Ca}^{2+}$ channels & {$[22]$} \\
\hline Cardiomyocytes(iPSC) & $1 \mu \mathrm{M}$ & $\begin{array}{l}\text { Ischemia/reperfusion and LPI } \\
\text { administration }\end{array}$ & $\begin{array}{c}\text { Reduced } \mathrm{Ca}^{2+} \text { overload providing ischemia/reperfusion } \\
\text { protection }(\downarrow \text { GPR55 activation, } \downarrow \text { RhoA, } \downarrow \text { ROCK) }\end{array}$ & {$[23]$} \\
\hline \multicolumn{5}{|l|}{ Ex vivo models } \\
\hline $\begin{array}{l}\text { Zucker diabetic rat } \\
\text { aorta }\end{array}$ & $10 \mu \mathrm{M}$ & Diabetic cardiomyopathy & Improved acetylcholine-induced vasorelaxation & {$[25]$} \\
\hline $\begin{array}{l}\text { Rat mesenteric } \\
\text { arteries }\end{array}$ & $10 \mathrm{mg} / \mathrm{kg}$ & Diabetic cardiomyopathy & $\begin{array}{c}\text { Endothelium COX- and NO-dependent enhanced } \\
\text { vasorelaxation of Ach }\end{array}$ & {$[26]$} \\
\hline $\begin{array}{l}\text { Human mesenteric } \\
\text { arteries }\end{array}$ & $10 \mu \mathrm{M}$ & Vasorelaxation & $\begin{array}{c}\text { Promotes vasorelaxation via CB1 and the TRP activation } \\
\text { and increased eNOS expression }\end{array}$ & {$[19]$} \\
\hline Rat aorta & $10 \mu \mathrm{M}$ & $\begin{array}{l}\text { Contraction stress by a } \\
\text { combination of U46619 and } \\
\text { methoxamine }\end{array}$ & $\begin{array}{c}\text { Increase vasorelaxation of precontracted aorta by } \\
\text { inhibition of calcium channels and increased } \\
\text { transcriptional activity of PPAR } \gamma\end{array}$ & {$[27]$} \\
\hline \multicolumn{5}{|l|}{ In vivo models } \\
\hline $\begin{array}{l}\text { Primary and } \\
\text { secondary } \\
\text { hypertension rat } \\
\text { model }\end{array}$ & $10 \mathrm{mg} / \mathrm{kg}$ & $\begin{array}{l}\text { Spontaneous and } \\
\text { deoxycorticosterone acetate- } \\
\text { salt hypertension }\end{array}$ & $\begin{array}{l}\text { Reduction of cardiac and plasma oxidative stress (increased } \\
\text { GSH and decreased GSSG) both in heart and plasma }\end{array}$ & {$[29]$} \\
\hline $\begin{array}{l}\text { Spontaneously } \\
\text { hypertensive rats }\end{array}$ & $\begin{array}{l}3,10 \text { and } \\
30 \mathrm{mg} / \mathrm{kg}\end{array}$ & Hypertension & $\begin{array}{c}\text { A dose-dependent decrease in HR and blood pressure } \\
\text { mediated via TRPV1 }\end{array}$ & {$[30]$} \\
\hline In vivo rat $I-R$ model & $5 \mathrm{mg} / \mathrm{kg}$ & $\begin{array}{l}\text { LAD ligation } \\
\text { ischemia/reperfusion injury }\end{array}$ & $\begin{array}{l}\text { A decrease in the infarct size and reduction of } \\
\text { inflammation molecules like IL- } 6\end{array}$ & {$[31]$} \\
\hline $\begin{array}{l}\text { In vivo } I-R \text { rabbit } \\
\text { model }\end{array}$ & $100 \mu \mathrm{g} / \mathrm{kg}$ & $\begin{array}{l}\text { Acute reperfusion myocardial } \\
\text { infarction }\end{array}$ & $\begin{array}{c}\text { Reduced infarct size and facilitated restoration of left } \\
\text { ventricular function }\end{array}$ & {$[32]$} \\
\hline In vivo rat $\mathrm{I}-\mathrm{R}$ model & $10,50 \mu \mathrm{g} / \mathrm{kg}$ & $\begin{array}{l}\text { LAD ligation } \\
\text { ischemia/reperfusion injury }\end{array}$ & $\begin{array}{l}\text { Reduction of the infarct size and ventricular arrhythmias } \\
\text { Inhibition of collagen-induced platelet aggregation }\end{array}$ & {$[33]$} \\
\hline In vivo I-R rat model & $50 \mu \mathrm{g} / \mathrm{kg}$ & $\begin{array}{l}\text { LAD ligation } \\
\text { ischemia/reperfusion -induced } \\
\text { ventricular arrhythmias }\end{array}$ & $\begin{array}{l}\text { Decreased incidence and duration of ventricular } \\
\text { tachycardia and the total length of arrhythmias by } \\
\text { activation of the adenosine } A_{1} \text { receptor }\end{array}$ & {$[34]$} \\
\hline Zucker diabetic rat & $10 \mu \mathrm{M}$ & Diabetic cardiomyopathy & $\begin{array}{l}\text { Improvement on vasorelaxation by involvement of the } \mathrm{CB}_{2} \\
\text { receptor and the enhancement of COX and SOD activity }\end{array}$ & {$[35]$} \\
\hline $\begin{array}{l}\text { Diabetic } \\
\text { cardiomyopathy } \\
\text { mice model }\end{array}$ & $\begin{array}{c}1,10 \\
20 \mathrm{mg} / \mathrm{kg}\end{array}$ & $\begin{array}{l}\text { Streptozotocin induced } \\
\text { diabetic cardiomyopathy }\end{array}$ & $\begin{array}{l}\text { Attenuated myocardial dysfunction, cardiac fibrosis, } \\
\text { oxidative/nitrosative stress, inflammation, and cell death }\end{array}$ & {$[11]$} \\
\hline $\begin{array}{l}\text { Autoimmune } \\
\text { myocarditis mice } \\
\text { model }\end{array}$ & $10 \mathrm{mg} / \mathrm{kg}$ & $\begin{array}{l}\text { MyHC } \alpha_{334-352} \text { induced } \\
\text { autoimmune myocarditis }\end{array}$ & $\begin{array}{l}\text { Attenuated the } \mathrm{CD}^{+} \text {and } \mathrm{CD} 4^{+} \mathrm{T} \text { cell-mediated } \\
\text { inflammatory response and injury, and myocardial fibrosis }\end{array}$ & {$[5]$} \\
\hline $\begin{array}{l}\text { Doxorubicin- } \\
\text { induced } \\
\text { cardiomyopathy } \\
\text { mice model }\end{array}$ & $5 \mathrm{mg} / \mathrm{kg}$ & $\begin{array}{l}\text { Doxorubicin-induced } \\
\text { cardiomyopathy }\end{array}$ & $\begin{array}{c}\text { Decreased serum creatine kinase-MB, } \mathrm{cTnT} \text {, cardiac } \\
\text { malondialdehyde, TNF- } \alpha, \mathrm{NO} \text { and } \mathrm{Ca}^{2+} \text { levels, increased } \\
\text { glutathione, selenium, and zinc ions levels }\end{array}$ & {$[36]$} \\
\hline
\end{tabular}


TABLe 1: Continued.

\begin{tabular}{lcccc}
\hline Biological subject & $\begin{array}{c}\text { CBD } \\
\text { concentration }\end{array}$ & Experimental model & CBD treatment key results & Ref \\
\hline $\begin{array}{l}\text { Doxorubicin- } \\
\text { induced } \\
\text { cardiomyopathy } \\
\text { mice model }\end{array}$ & $10 \mathrm{mg} / \mathrm{kg}$ & $\begin{array}{c}\text { Doxorubicin-induced } \\
\text { cardiomyopathy }\end{array}$ & $\begin{array}{c}\text { Attenuated oxidative and nitrative stress, improved } \\
\text { mitochondrial function, and biogenesis }\end{array}$ & [37] \\
$\begin{array}{l}\text { In vivo rat stress } \\
\text { model }\end{array}$ & $1-72 \mathrm{mg} / \mathrm{kg}$ & Restraint stress & Abolished increase of HR and MAP by activation of 5- & {$[38-$} \\
\hline
\end{tabular}

than normotensive rats. However, the study reported that in conscious rats, the effect was not observed due to a slowly infused intraperitoneal (i.p.) administration of CBD.

\subsubsection{Use of CBD on Ischemia/Reperfusion and Arrhythmias.} The cardioprotective effect of CBD has been studied in different cardiomyopathies, including ischemia/reperfusion (I-R) and arrhythmias. Durst et al. [31] studied the protection provided by $C B D$ after I-R injury. Decreased infarct size was observed when Sprague-Dawley rats were treated with CBD, while the area at risk was similar to the control group. There were no differences in myocardial contractility or remodeling parameters. Furthermore, the inflammatory response was lower in CBD-treated hearts than in the I-R group, including decreased levels of IL-6, suggesting that the cardioprotective effect of CBD may be caused by a systemic immunomodulatory effect. Feng et al. [32] observed the facilitated restoration of the left ventricular function when rabbits were administered with CBD. Walsh et al. [33] tested the effect of CBD on cardiac arrhythmias and the infarct size when administered immediately before I-R on Sprague-Dawley rats. Administering CBD caused a reduction in the infarct size and collagen-induced platelet aggregation, as well as significantly reduced the number of ischemiainduced ventricular arrhythmias compared to the vehicletreated group. Similarly, using an in vivo I-R model, Gonca et al. [34] observed a decreased incidence and duration of ventricular tachycardia on Wistar rats. These studies show that CBD may be beneficial in the prevention of arrhythmias caused by different conditions, such as heart failure.

\subsubsection{Use of $C B D$ on Cardiomyopathies with Concurrent} Diseases. The clinical outcomes associated with heart failure are considerably worse for patients with concurrent diseases, such as immunological pathologies or diabetes mellitus. Therefore, CBD represents a potential treatment for cardiovascular complications, including diabetic cardiomyopathy, which is characterized by myocardial left ventricular dysfunction. Wheal et al. [35] found that CBD improved vasorelaxation in diabetic rats, as there was a $40 \%$ increase in vasorelaxation in diabetic rats when compared to lean rats. Meanwhile, Rajesh et al. [11] found during diabetic cardiomyopathy that attenuated cardiac fibrosis and oxidative/nitrosative stress improve myocardial function. In a model of autoimmune myocarditis, Lee et al. [5] observed that CBD provides inflammatory and injury protection. Administration of CBD to immunocompromised mice caused a decrease in T-cell markers as well as monocyte cell activators. These
CBD-treated mice showed a lower $\mathrm{CD}^{+}$and $\mathrm{CD}^{+} \mathrm{T}$-cellmediated inflammatory response and decreased myocardial injury and fibrosis.

CBD may play an important role in cardioprotection when heart injury is caused by the treatment of another pathology, like doxorubicin, an anticancer antibiotic known for its cardiotoxicity. Regarding, Fouad et al. [36] reported in vivo $\mathrm{CBD}$ cardioprotection. In the study, $\mathrm{CBD}$ caused a decrease in several heart injury markers elevated by doxorubicin, including serum creatine kinase-MB and cardiac troponin $\mathrm{T}(\mathrm{c} T n \mathrm{~T})$, and cardiac malondialdehyde attenuated inflammation and oxidative stress. Similarly, Hao et al. [37], using an in vivo doxorubicin-induced cardiomyopathy model, observed attenuated cardiac oxidative and nitrative stress and improved mitochondrial function and biogenesis which may contribute to its beneficial properties in tissue injury.

2.4.4. Use of CBD on Cardiac Stress Conditions. Different kinds of stress may stimulate the sympathetic nerve activity affecting systemic metabolism. Resstel et al. $[38,39]$ and Gomes et al. [40] studied the effect of CBD on cardiovascular responses induced by restraining movement. Stress caused an increase in the animals' mean arterial pressure and heart rate. Pretreatment with CBD did not affect the baseline of the cardiovascular parameters, but it attenuated the increase in HR and mean arterial pressure (MAP) in stressed animals. CBD caused a reduction of pressure and tachycardic responses in a dose-dependent manner. Similarly, Granjeiro et al. [41] observed attenuation of the increase in MAP and HR after restraint stress in rats administered CBD. The results in these studies indicate there were no changes in the baselines of cardiovascular parameters within the control group, suggesting that CBD may act specifically on stress-related cardiovascular pathways.

2.5. Proposed Mechanisms and Molecular Pathways of CBD from Different Cardiovascular Models. Based on the collected evidence in the studied models pointing to $\mathrm{CBD}$ as a promising cardioprotective therapy, we performed a thorough analysis of the pleiotropic mechanisms involved, as well as molecular pathways and target molecules that are, to some extent, affected by the CBD administration. We identified five main mechanisms modulated by CBD that are responsible for the beneficial effects observed in cardiac dysfunction and heart failure: (a) oxidative and nitrosative stress, (b) the inflammatory state, (c) effect on vasorelaxation, (d) the regulation of cardiac contractibility, and (e) antiproliferative and 


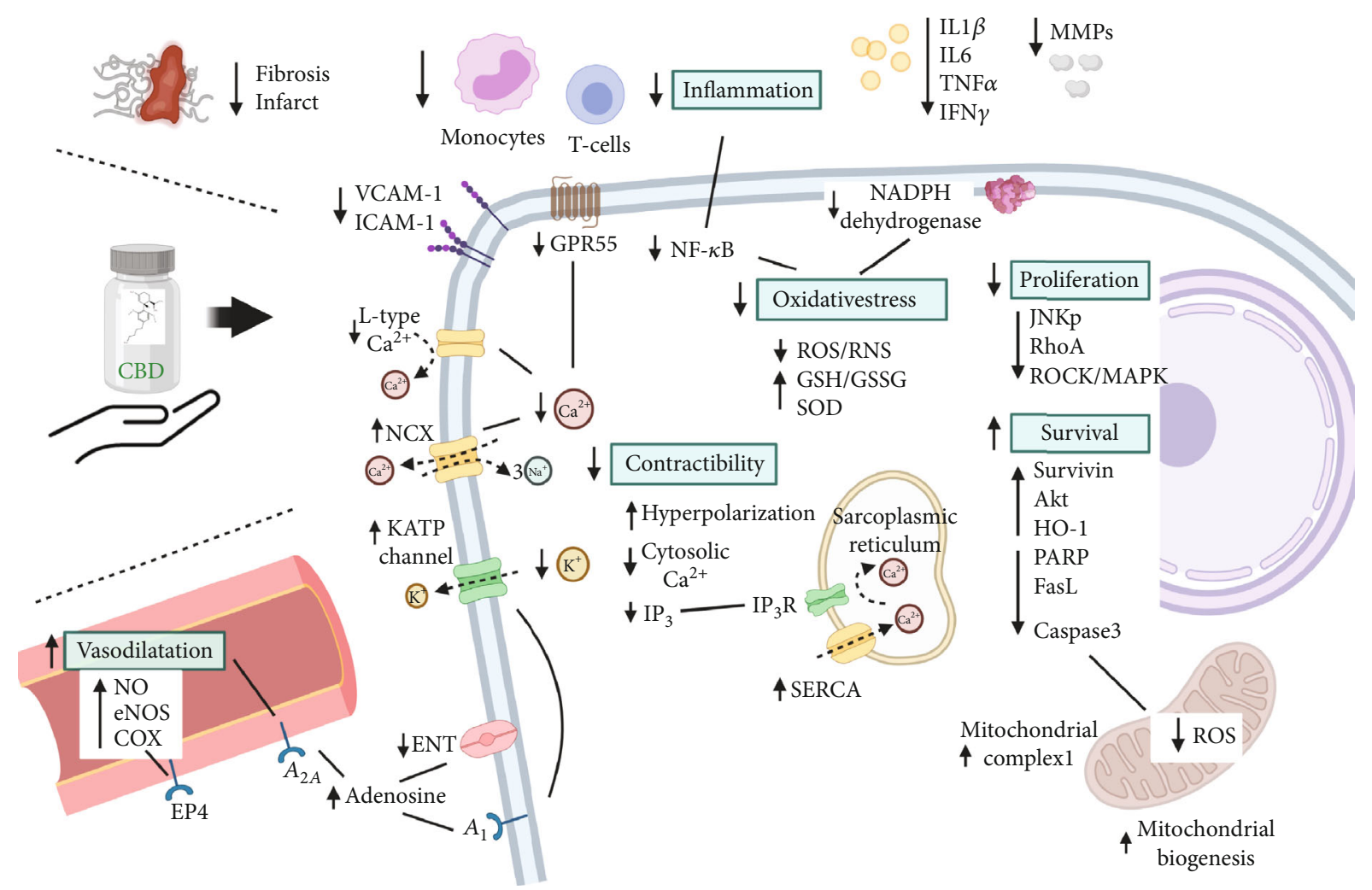

FIGURE 2: Mechanisms and molecular pathways of the CBD administration in the cardiovascular system. CBD is involved in regulating several pathways, protecting cardiomyocytes from inflammation and oxidative stress, regulating the $\mathrm{Ca}^{2+} / \mathrm{K}^{+}$intake, decreasing immune proliferation, and promoting cellular survival. CBD helps to protect mitochondria and regulates their biogenesis, improving the cellular energy supply. In vascular vessels, CBD causes vasodilatation, lowering blood pressure, and protecting the heart. Arrows indicate changes in activity for each molecule/mechanism/inflammatory cell.

antiapoptotic properties. All of these mechanisms are explained in greater detail below and summarized in Figure 2.

2.5.1. Oxidative and Nitrosative Stress. CBD is well known as a potent antioxidant due to its capacity to modulate the production of reactive oxygen and nitrogen species (ROS/RNS). Rajesh et al. [11] observed that the production of superoxide anion radicals was diminished by CBD treatment as a result of the reduced mRNA expression of the NADPH oxidase subunits p22phox, p67phox, and gp91phox, which are components of the oxidase system. CBD also reduces superoxide anion by increasing SOD and the glutathione peroxidase activity $[1,2]$, elevating the GSH/GSSG ratio, and reducing lipid peroxidation and protein carbonyl groups formation $[11,36,37]$. CBD redox protection is not limited to its antioxidant properties modulating ROS production and degradation. It also has a significant impact on reducing nitric oxide- (NO-) mediated stress by decreasing peroxynitrite and nitrotyrosine formation [36], limiting the generation of 4-hydroxynonenal (4-HNE), most likely by reducing lipid peroxidation, resulting in a marked reduction in the 3nitrotyrosine (3-NT) generation $[5,11]$, which is indicative of a protective effect against RNS damage.

The role of mitochondria in cellular redox reactions is one of the most important contributions to electron transfer balance. Hao et al. [37] observed the cardiotoxicity derived from the use of doxorubicin which can be attenuated by CBD therapy, as it can activate mitochondrial complex 1 providing additional oxidative protection accompanied by an increase in the number of mitochondria and biogenesis stimulation. The mechanism that involves mitochondrial ROS production and biogenesis possibly depends on the mitochondrial $\mathrm{Ca}^{2+}$ uptake promoting the dephosphorylation of transcription factor A (TFAM), which consequently induces mitochondrial biogenesis [42].

2.5.2. Inflammation. Most cardiac pathologies result in chronic inflammation, cellular damage, and subsequently, cell death and fibrotic tissue formation. In this context, $\mathrm{CBD}$ has been widely proven to be a major mediator of inflammation by reducing the expression of inflammatory cytokines $[5,11,36]$, decreasing the production of adhesion molecules $[11,20]$ and matrix metallopeptidases (MMPs) [37] and consequently limiting the damage caused by the migration and infiltration of immune cells in the cardiac tissue. According to Fouad et al. [36], one of the most important targets of CBD in the inflammatory pathway is NF- $\kappa \beta$, restraining its phosphorylation and nuclear internalization, a mechanism most likely mediated via ROS reduction [19, $36,37]$. As a result of NF- $\kappa \beta$ inhibition by CBD in the evaluated experimental models, there is a diminished expression 
of cytokines, lower infiltration by T-cells and neutrophils, and reduced IFN- $\gamma$ [43] and myeloperoxidase secretion by these cells [32]. Thus, CBD limits damage to the extracellular matrix, decreases monocytic invasion, which can differentiate in myofibroblasts $[31,32]$, and decreases the production of collagen [11] and fibrosis formation, resulting in the maintenance of cardiac function. With lower collagen production, a decrease in collagen-induced platelet aggregation has been observed [33,34], a condition exacerbated in ischemic conditions, dampening the risk of thrombotic formation.

In the animal models of myocardial infarction, the CBD administration improved the cardiovascular function, as evidenced by reductions in the infarct size and the area of fibrosis, as well as lower blood levels of IL-6 [31] and cardiac troponin cTnI, which are markers of tissular damage [32]. Furthermore, in chronic inflammatory diseases, tryptophan metabolism is affected, leading to a failure in the capacity of these patients to properly activate an immune response. $\mathrm{CBD}$ has a beneficial effect on these patients by reducing the indoleamine-2,3-dioxygenase (IDO) enzyme activity, which is responsible for converting tryptophan into kynurenine metabolites. The IDO enzyme activity is induced by IFN- $\gamma$, and the CBD administration prevents its activation $[33,43]$. Tryptophan is also necessary for the synthesis of $\mathrm{NAD}^{+}$, which is an oxidizing agent, and serotonin, a neurotransmitter responsible for the antidepressant effect of cannabinoids, thus impacting the patient's mood and quality of life $[33,43]$.

2.5.3. Vasorelaxation. Of the proposed mechanisms of CBD cardioprotection, vasorelaxation undoubtedly plays a major role in limiting damage to the cardiac tissue over time in the presence of hypertension, heart failure, and chronic vascular diseases. CBD stimulates the production of endothelial nitric oxide synthase (eNOS) [19] and hence, vasorelaxation via nitric oxide (NO) synthesis [36, 37].

Stanley et al. [19] stated that the vasorelaxant effect of CBD is mediated by activating CB1 receptors and transient receptor potential (TRP) channels, as the use of an antagonist for both inhibited vasorelaxation. In the same study, CBD also activated endothelial-bound cannabinoid receptor(CBe-) mediated vasorelaxation, but it does not seem to be a direct interaction. Another strong candidate for a direct target is PPAR- $\gamma$. Although CBD has been proven to be a functional agonist of this receptor, it lacks the adverse side effects reported with the use of PPAR- $\gamma$ agonists, namely, weight gain, fluid retention, and congestive heart failure. However, antagonizing this receptor only partially reduced the CBD vasorelaxant effect [27].

In arteries, the CBD enhanced COX activity, stimulating the production of prostaglandin E2, a potent smooth muscle vasodilator, activating EP4 receptors as described by Wheal et al. $[26,35]$. In the endothelium, the COX activity may be mediated by the acetylcholine (ACh) via eNOS activation $[26,35]$. CBD is known to suppress cellular adenosine intake, hence increasing its interstitial concentration and resulting in increased $A_{2} a$ receptor activation and elevated NO production in the smooth muscle, causing vasodilatation $[36,37]$. Notably, iNOS' contribution to CBD vasorelaxation appears to be negligible since its expression is downregulated by CBD, most likely because iNOS is activated by NF- $\kappa \beta$ and other pr-inflammatory stimuli, such as TNF- $\alpha$, which are suppressed by CBD [11, 20, 37].

2.5.4. Cardiac Contractility. The effects of endocannabinoids on the heart have been widely studied. They have protective functions in the cardiac tissue under stressful conditions, such as arrhythmias and myocardial infarction [44]. CBD has multiple interactions with ion channels and membrane receptors that alter the distribution of electrical charges inside the cell, modulating myocyte contractility. In $\mathrm{Ca}^{2+}$ homeostasis, $\mathrm{CBD}$ causes the inhibition of L-type $\mathrm{Ca}^{2+}$ channels, impeding the internalization of additional $\mathrm{Ca}^{2+}$ from the interstitial medium. When coupled with a reduction in the $\mathrm{IP}_{3}$-mediated release of $\mathrm{Ca}^{2+}$ from the sarcoplasmic reticulum, it results in difficulty depolarizing the cellular membrane, restraining the triggering of the myocyte action potential [23]. In pathological conditions involving high extracellular $\mathrm{K}^{+}$, CBD can modulate the activation of the $\mathrm{Na}^{+} / \mathrm{Ca}^{2+}$ exchanger (NCX) to release additional $\mathrm{Ca}^{2+}$ from the cytosol into the extracellular space [33]. Furthermore, by reducing the oxidative and inflammatory cascade, CBD can preserve the SERCA activity and promote $\mathrm{Ca}^{2+}$ storage in the sarcoplasmic reticulum [45]. Through these effects, the ionic balance is protected, and cytosolic overload is reduced [5] In this context, proarrhythmogenic events can be triggered by serum mediators of chronic inflammation modifying spontaneous $\mathrm{Ca}^{2+}$ release events, which provide a substrate for ventricular arrhythmias [46].

At the mitochondrial level, CBD has minor influence over mitochondrial $\mathrm{Ca}^{2+}$ regulation, as Walsh et al. [33] described a lack of CBD participation in the mitochondrial permeability transition. Interestingly, $\mathrm{CBD}$ can antagonize the activation of the GPR55 receptor [23], avoiding $\mathrm{IP}_{3}$ dependent $\mathrm{Ca}^{2+}$ liberation from the sarcoplasmic reticulum, limiting the entry of $\mathrm{Ca}^{2+}$ into the mitochondria during ischemia/reperfusion, and preventing further injury caused by the overflow of $\mathrm{Ca}^{2+}$. In this sense, avoiding mitochondrial $\mathrm{Ca}^{2+}$ overload has been established as a paradigm of cardioprotection in cardiac ischemia/reperfusion injury $[47,48]$.

CBD has a wide influence over the cellular membrane's capacity to regulate the ionic balance. CBD acts as a competitive inhibitor of the equilibrate nucleoside transporter (ENT), impeding the cellular uptake of adenosine, augmenting its extracellular concentration, and allowing the increased activation of adenosine $A_{1}$ receptors $[34,39,41]$, which, in turn, activates potassium $\mathrm{K}^{+}$-ATP channels and causes hyperpolarization of the cell membrane, producing an antiarrhythmic effect by decreasing cardiomyocyte excitability $[19,27,33,34]$. Finally, CBD is also an agonist of 5-HT1A receptors, acting as an anxiolytic, possibly lowering the mean arterial blood pressure, producing sympathetic inhibition, and reducing ventricular arrhythmias $[39,41]$.

2.5.5. Antiproliferative and Antiapoptotic Effects. Treatment with $\mathrm{CBD}$ can prevent cellular and tissular events, such as ischemia/reperfusion, and to some extent, reduce the infarct size. The mechanisms involved are a combination of the 
promotion of cellular survival, the inhibition of apoptosis, and extracellular matrix conservation by avoiding immune cellular expansion and migration. It has been noted that the enzyme HO-1 participates in protecting the cardiac and vascular tissue from aberrant cellular proliferation and migration. Schwartz et al. [18] demonstrated the role of $\mathrm{CBD}$ in upregulating the expression of $\mathrm{HO}-1$, thus providing cardioprotection. In the presence of an inflammatory process, the HO-1 pathway activation by CBD could be of great importance to limit tissular damage from immune cell proliferation and invasion, as these cells' mitosis is activated by ROS via the induction of JNK phosphorylation [11, 19]. The CBD administration can also be beneficial to stressed cardiac cells by inducing the expression of survivin [36] and Akt phosphorylation [11, 19], both of which influence cell survival.

Under ischemia/reperfusion injury, CBD attenuates the RhoA activation [23] and its pathways ROCK/p38 and MAPK/MAPKAPK2 [11, 23], which are activated in response to inflammatory and proliferative stimuli. CBD plays a significant antiapoptotic role by protecting the cell from oxidative damage and $\mathrm{Ca}^{2+}$ overload, preventing the activation of caspase 3 cleavage, PARP activity, FasL expression, and chromatin fragmentation [11, 36, 37]. Both the antiproliferative and the antiapoptotic effects are naturally modulated by the action of endocannabinoids. CBD is known to inhibit the enzyme fatty acid amide hydrolase (FAAH), resulting in increased levels of available systemic endocannabinoids [35], which is an indirect mechanism of cellular protection.

2.6. Other Cannabinoids of Cardiac Significance. The endocannabinoid system has two distinct membrane receptors, $\mathrm{CB}_{1}$ and $\mathrm{CB}_{2}$, which are activated through endogenous cannabinoid ligands, as well as plant-derived cannabinoids and their synthetic analogs. However, some cannabinoids exhibit vasodilator effects via endothelial receptors distinct from $\mathrm{CB}_{1}$ and $\mathrm{CB}_{2}$ [49]. Table 2 summarizes the use of cannabinoids in different cardiomyopathies.

2.6.1. Cardioprotective Effect of Cannabinoids against Ischemia/Reperfusion Injury. A variety of mechanisms of protection from cardiac ischemia-reperfusion injury implicate endocannabinoids. Ischemic preconditioning is well known for its potent cardioprotective effects, resulting in smaller infarct sizes, reduced risk of I-R arrhythmias, and improved recovery of ventricular function. Joyeux et al. [50] reported that isolated hearts preconditioned with heat stress reduced the infarct size significantly after an I-R sequence. This protection was abolished when treating isolated hearts with a $\mathrm{CB}_{2}$ receptor antagonist, SR144528, implicating the $\mathrm{CB}_{2}$ receptor in the observed cardioprotection.

Lépicier et al. [51] studied the protective effect of arachidinoylethilenamide (i.e., anandamide [ACEA]), 2arachidonoylglycerol (2-AG), and palmitoylethanolamide (PEA) (agonists of $\mathrm{CB}_{1}$ and $\mathrm{CB}_{2}$ receptors) against I-R. They observed that treatment with PEA and 2-AG allowed the heart function recovery during reperfusion in terms of maximum $\mathrm{dP} / \mathrm{dt}$ and left ventricular end-diastolic pressure
(EDP). In presence of rimonabant (SR141716A), a selective $\mathrm{CB}_{1}$ antagonist, it still allowed the complete function recovery by PEA but cut the function recovery of $2-A G$ in half. However, the $\mathrm{CB}_{2}$ inverse agonist SR144528 allowed no recovery by PEA or 2-AG. They also observed that PEA and 2-AG decreased the levels of creatine kinase (CK) and lactate dehydrogenase (LDH), two biochemical markers of ischemic injury, as well as the infarct size. The decreased levels of CK and $\mathrm{LDH}$ were absent when treating hearts with anandamide. Using ACEA and JWH015, synthetic agonists of $\mathrm{CB}_{1}$ and $\mathrm{CB}_{2}$ receptors, respectively, activated these receptors and could protect the heart from ischemia. Also, using SB203580 and PD98059, inhibitors of p38 MAP kinase and the ERK1/2 pathway, respectively, demonstrated the participation of $\mathrm{p} 83$ and ERK1/2 in the cardioprotective effects of PEA, as the protection was abolished when using the inhibitors.

The contribution of endogenous cannabinoids in the protective effect of I-R on endothelial function was reported by Bouchard et al. [52]. They analyzed the vasodilatory response to serotonin (5-HT) and sodium nitroprusside (SNP). Hearts submitted to a preconditioning ischemia treatment preserved 5-HT vasodilatory effects. Meanwhile, the presence of either SR141716A or SR144528 abolished the 5-HT vasodilatory response, suggesting endogenous cannabinoids play a role in endothelial protection by acting on $\mathrm{CB}_{1}$ and $\mathrm{CB}_{2}$ receptors. This role was confirmed by perfusion with $2-\mathrm{AG}, \mathrm{PEA}$, and anandamide following I-R. Perfusion with both $2-A G$ and PEA prevented an ischemia-induced reduction in vasodilation due to 5-HT, as they mimic the protection of preconditioning on the endothelial function. However, Underdown et al. [53] reported a significant reduction in the infarct size when using anandamide or methanandamide, its nonhydrolyzable analog. This protective effect was blocked when treated with either SR141716A or SR144528, $\mathrm{CB}_{1}$, and $\mathrm{CB}_{2}$ receptors antagonists, respectively. They suggest that the infarct-limiting action of anandamide requires costimulation of $\mathrm{CB}_{1}$ and $\mathrm{CB}_{2}$ receptors, as well as interaction with another cannabinoid receptor subtype, considering that the use of both ACPA or JWH-133, agonists of $\mathrm{CB}_{1}$ and $\mathrm{CB}_{2}$, respectively, did not mimic the effect of anandamide. Similarly, in anesthetized rats, Zakrzeska et al. [54] observed that anandamide and methanandamide caused a decrease in MBP without affecting $\mathrm{HR}$, and these effects were reduced by $\mathrm{CBD}$ and O-1918, a GPR18 antagonist, suggesting the participation of other receptors, in addition to $\mathrm{CB}_{1} / \mathrm{CB}_{2}$ receptors.

Using the synthetic ligands of the $\mathrm{CB}_{2}$ receptor WIN55212-2 and JWH-133, Di Filippo et al. [55] and Montecucco et al. [56] demonstrated that the $\mathrm{CB}_{2}$ receptor activation confers protection against myocardial damage associated with I-R. The protective effect was abolished by $A M 630$, a highly selective $\mathrm{CB}_{2}$ receptor antagonist. Furthermore, WIN55212-2 inhibited the local generation of leukocyte activators, cytokines, and chemokines, which are promoters of leukocyte-endothelium interaction, causing the inhibition of leukocyte-dependent damage of infracted myocardium [55], and JWH-133 reduced the production of superoxide species significantly and increased ERK1/2 and 
TABLE 2: Use of cannabinoids in different cardiomyopathies.

\begin{tabular}{|c|c|c|c|c|}
\hline Compound & Pharmacological activity & $\begin{array}{l}\text { Cardiomyopathy } \\
\text { model }\end{array}$ & Observed effect & Reference \\
\hline \multirow{3}{*}{ SR144528 } & \multirow[t]{3}{*}{$\mathrm{CB}_{2}$ antagonist } & \multirow[t]{2}{*}{$\mathrm{I}-\mathrm{R}$} & $\begin{array}{l}\text { Abolished cardioprotection of ECS, PEA, } \\
\text { 2-AG, ACEA, and methanandamide }\end{array}$ & $\begin{array}{l}{[50,51} \\
53]\end{array}$ \\
\hline & & & Abolished 5-HT vasodilatory response & {$[52]$} \\
\hline & & Arrhythmia & No effect over ACEA protection & [58] \\
\hline \multirow{5}{*}{ SR141716A (rimonabant) } & \multirow{5}{*}{$\mathrm{CB}_{1}$ antagonist } & & $\begin{array}{l}\text { No effect over ECS and PEA } \\
\text { cardioprotection }\end{array}$ & {$[50,51]$} \\
\hline & & $\mathrm{I}-\mathrm{R}$ & $\begin{array}{l}\text { Abolished ACEA, methanandamide, and } \\
\text { half 2-AG cardioprotection }\end{array}$ & {$[51,53]$} \\
\hline & & & Abolished 5-HT vasodilatory response & {$[52]$} \\
\hline & & MI & Prevention of hypotention followed by MI & {$[62]$} \\
\hline & & Arrhythmia & $\begin{array}{l}\text { No effect over ACEA and HU.210 } \\
\text { protection }\end{array}$ & {$[58,59]$} \\
\hline \multirow{5}{*}{$\begin{array}{l}\text { Anandamide } \\
\text { (arachidinoylethilenamide, } \\
\text { ACEA) }\end{array}$} & \multirow{5}{*}{$\begin{array}{l}\text { Endogenous cannabinoid, } \\
\qquad \mathrm{CB}_{1} \text { and } \mathrm{CB}_{2} \text { agonist }\end{array}$} & \multirow{2}{*}{$\mathrm{I}-\mathrm{R}$} & Heart protection against ischemia & [51] \\
\hline & & & Reduction of the infarct size & {$[53]$} \\
\hline & & \multirow{2}{*}{ Arrhythmia } & $\begin{array}{l}\text { Increase resistance to arrhythmogenic } \\
\text { effects of epinephrine }\end{array}$ & [58] \\
\hline & & & $\begin{array}{c}\text { Improvement on cardiac resistance to } \\
\text { arrhythmia }\end{array}$ & {$[60]$} \\
\hline & & $\begin{array}{l}\text { Pulmonary artery } \\
\text { hypertension }\end{array}$ & $\begin{array}{l}\text { Endothelium-dependent pulmonary artery } \\
\text { relaxation }\end{array}$ & [70] \\
\hline \multirow{2}{*}{$\begin{array}{l}\text { 2-arachidonoylglycerol } \\
(2-A G)\end{array}$} & \multirow{2}{*}{$\begin{array}{l}\text { Endogenous cannabinoid, } \\
\qquad \mathrm{CB}_{1} \text { and } \mathrm{CB}_{2} \text { agonist }\end{array}$} & \multirow[b]{2}{*}{$\mathrm{I}-\mathrm{R}$} & Heart function recovery after reperfusion & {$[51]$} \\
\hline & & & $\begin{array}{l}\text { Protection of preconditioning on the } \\
\text { endothelial function }\end{array}$ & {$[52]$} \\
\hline \multirow{3}{*}{ Palmitoylethanolamide (PEA) } & \multirow{3}{*}{$\begin{array}{l}\text { Endogenous cannabinoid, } \\
\qquad \mathrm{CB}_{1} \text { agonist }\end{array}$} & \multirow{3}{*}{$\mathrm{I}-\mathrm{R}$} & Heart function recovery after reperfusion & [51] \\
\hline & & & $\begin{array}{l}\text { Protection of preconditioning on the } \\
\text { endothelial function }\end{array}$ & {$[52]$} \\
\hline & & & No effect on infarct reduction & {$[53]$} \\
\hline JWH105 & $\mathrm{CB}_{2}$ agonist & $\mathrm{I}-\mathrm{R}$ & Heart protection against ischemia & {$[51]$} \\
\hline \multirow{2}{*}{ Methanandamide } & $\begin{array}{l}\text { Non-hydrolyzable } \\
\text { anandamide analog }\end{array}$ & $\mathrm{I}-\mathrm{R}$ & Reduction of the infarct size & {$[53]$} \\
\hline & & Arrhythmia & $\begin{array}{c}\text { Improvement on cardiac resistance to } \\
\text { arrhythmia }\end{array}$ & {$[60]$} \\
\hline \multirow{2}{*}{ JWH-133 } & \multirow{2}{*}{$\mathrm{CB}_{2}$ agonist } & \multirow{2}{*}{$\mathrm{I}-\mathrm{R}$} & No effect on infarct reduction & [53] \\
\hline & & & Reduction of myocardial injury & [56] \\
\hline WIN55212-2 & $\mathrm{CB}_{2}$ ligand & $\mathrm{I}-\mathrm{R}$ & Protection against myocardial damage & {$[55]$} \\
\hline AM630 & $\mathrm{CB}_{2}$ antagonist & $\mathrm{I}-\mathrm{R}$ & $\begin{array}{l}\text { Abolished cardioprotection of } \\
\text { WIN55212-2 and JWH-133 }\end{array}$ & {$[55,56]$} \\
\hline AM251 & $\mathrm{CB}_{1}$ antagonist & $\mathrm{I}-\mathrm{R}$ & No effect on WIN55212-2 cardioprotection & {$[55]$} \\
\hline \multirow[t]{2}{*}{ HU-210 } & \multirow[t]{2}{*}{$\mathrm{CB}_{1}$ and $\mathrm{CB}_{2}$ agonist } & $\mathrm{I}-\mathrm{R}$ & $\begin{array}{l}\text { Cardioprotection by mimic } \\
\text { postconditioning }\end{array}$ & {$[57]$} \\
\hline & & Arrhythmia & Antiarrhythmic effects & {$[59]$} \\
\hline Abnormal cannabidiol & Regioisomer of CBD & $\begin{array}{c}\text { Diabetic } \\
\text { cardiomyopathy }\end{array}$ & $\begin{array}{l}\text { Hemodynamic, reduction of LV } \\
\text { contractility and relaxation index }\end{array}$ & {$[63,64]$} \\
\hline
\end{tabular}

STAT-3 phosphorylation, pathways involved in cardioprotection [56].

Gorbunov et al. [57] reported the use of the $\mathrm{CB}_{1}$ and $\mathrm{CB}_{2}$ agonist $\mathrm{HU}-210$ to reduce the infarction effect of reperfusion after local ischemia in the heart by mimicking the postconditioning phenomenon. In the study, HU-210 decreased the infarction size in the area at the risk ratio significantly, preventing reperfusion injury after ischemia. HU-210 decreased the pumping function of the heart, leading to a reduction of its work and oxygen demand during reperfusion, probably promoting cardiomyocyte survival during reperfusion. Moreover, HU-210 decreased end-diastolic pressure values 
during the reperfusion period, suggesting a reduction in the $\mathrm{Ca}^{2+}$ overload of cardiomyocytes.

2.6.2. Cardioprotective Effect of Cannabinoids against Arrhythmias. Coronary occlusion and reperfusion cause arrhythmogenic effects in the myocardium, mostly modulated by a variety of neurotransmitters with the cardiovascular activity. Ugdyzhekova et al. [58] reported an increase of $50 \%$ in rats resistant to arrhythmogenic effects caused by epinephrine when treated with anandamide. The use of SR141716A and SR144528 did not affect the antiarrhythmic activity of anandamide, suggesting that the effect is mediated via anandamide receptors localized in the myocardium other than $\mathrm{CB}_{1}$ and $\mathrm{CB}_{2}$. They also suggest that the antiarrhythmic effect is caused by a decrease in the cAMP activity of L-type $\mathrm{Ca}^{2+}$ channel blockage in cardiomyocytes. Using the agonist HU-210, Ugdyzhekova et al. [59] reported an antiarrhythmic effect of the agonist by activating $\mathrm{CB}_{2}$ receptors and inhibiting cAMP synthesis, which acts as an arrhythmogenic factor. Using an I-R model, Krylatov et al. $[60,61]$ tested anandamide and methanandamide improvement in cardiac resistance to arrhythmias, observing that both cannabinoids possess the antiarrhythmic activity. Using L-NAME and glibenclamide as an inhibitor of $\mathrm{NO}$ synthase and $\mathrm{K}_{\mathrm{ATP}}$ channels, respectively, no changes in the antiarrhythmic activity of both cannabinoids were observed. This suggests that the antiarrhythmic effect of endocannabinoids is not associated with the activity of NO synthase and $\mathrm{K}_{\mathrm{ATP}}$ channels but is correlated with $\mathrm{CB}_{2}$ receptor stimulation.

2.6.3. Hemodynamic Effect of Cannabinoids. Endocannabinoids play a crucial role in hemodynamic changes, a common complication of acute myocardial infarction (MI), and other cardiomyopathy complications. Wagner et al. [62] reported the contribution of activated vascular $\mathrm{CB}_{1}$ receptors to hypotension after experimental MI. Use of the $\mathrm{CB}_{1}$ antagonist SR141716A prevented hypotension after MI but aggravated early endothelial dysfunction and had a detrimental effect on early survival, similar to hemorrhagic shock. Endocannabinoid-induced vasodilation in cardiogenic shock also helps maintain adequate tissue perfusion in the face of decreased cardiac output and a compensatory increase in sympathetic vasoconstrictor tone. Matouk et al. [63, 64] reported a cardioprotective effect of abnormal cannabidiol (abn-CBD), a synthetic regioisomer of CBD, using in vivo diabetic cardiomyopathy models. Hemodynamic effects were studied by the chronic activation of the endocannabinoid receptor GPR18 in the absence or presence of O-1918, a GPR18 antagonist. Abn-CBD reduced blood pressure significantly with no effect on the heart rate, improved the left ventricular contractility index, and reduced LVEDP. The blockage of GPR18 with O-1918 abolished the effects obtained with abn-CBD. The observed hypotension caused by abn-CBD was associated with an increase in aortic endothelium-nitric oxide synthesis and in circulating $\mathrm{NO}$ and cGMP. Although abn-CBD did not influence hypertrophy or impaired glycemic control, it alleviated the diabetesinduced reduction in LV contractility and the relaxation index, LVEDP. These effects were observed due to the ability of abn-CBD to alleviate reductions in circulating adiponectin $(\mathrm{ADN})$ and NO levels, increasing the myocardial GPR18 expression, reversing elevation in the cardiac AdipoR1 expression, as well as restoring myocardial Akt, ERK1/2, and eNOS phosphorylation, and restoring $\mathrm{NO}$ levels and redox status. GPR18 likely mediates cardioprotection because the concurrent administration of O-1918 with abnCBD abolished the functional and biochemical responses $[65,66]$. Similarly, virodhamine, a recently identified endocannabinoid, may act as an endothelium-dependent vasorelaxant compound via the abn-CBD receptor (GRP18) given that O-1918 inhibited the relaxation that virodhamine caused on isolated rat mesenteric arteries, as reported by Ho et al. [67], via activation of the $\mathrm{Ca}^{2+}$-activated $\mathrm{K}^{+}$channel. However, Bondarenko et al. [68] reported that abn-CBD might mediate the vasodilation activity via the GPR-18independent activation of high-conductance $\mathrm{Ca}^{2+}$-activated $\mathrm{K}^{+}$channels $\left(\mathrm{BK}_{\mathrm{Ca}}\right)$ in mice aorta endothelial cells. Additionally, Ho et al. [69] determined that the relaxing effect of abnCBD in the small mesenteric arteries of rats is caused by the endothelium-dependent $\mathrm{K}^{+}$channel activation and $\mathrm{Ca}^{2+}$ channel inhibition. Baranowska-Kuczko et al. [70] observed the effect of anandamide in rat pulmonary arteries. Anandamide caused the endothelium-dependent vasorelaxation of precontracted pulmonary arteries with U-46619 by activating O-1918-sensitive endothelial cannabinoid receptors. In another study, Su et al. [71] observed the relaxation of permeabilized pulmonary arteries by 2-AG ether, a metabolically stable cannabinoid, and that abn-CBD is mediated by $\mathrm{CB} 1$ and abn-CBD receptors. This effect suggests the potential use of endocannabinoids, such as anandamide and 2AG, in the treatment of pulmonary arterial hypertension. A similar endothelium-dependent vasorelaxation effect was observed by Milman et al. [72] in the isolated mesenteric arteries and abdominal aorta of rats caused by $\mathrm{N}$-arachidonoyl-L-serine, an anandamide chemically related compound. During liver cirrhosis, heart functions are compromised, causing hyperdynamic circulation and leading to systemic hypotension and decreased peripheral resistance, termed cirrhotic cardiomyopathy. An in vivo model reported by Bátkai et al. [73] indicated an increased concentration of anandamide in the heart of cirrhotic rats, acting as an endogenous agonist of the contractile dysfunction associated with liver cirrhosis. The use of a $\mathrm{CB}_{1}$ antagonist, $\mathrm{AM} 251$, corrected the altered hemodynamic functions in cirrhotic rats, causing a gradual increase of MAP, but it caused no changes in normal rats. Cardiac hypertrophy, characterized by increased myocardial mass due to hemodynamic stress or cardiac injury, is considered a risk factor of heart failure. Using CB13 , a $\mathrm{CB}_{1} / \mathrm{CB}_{2}$ dual agonist, Lu et al. [74] decreased in vitro hypertrophy in the ventricular myocytes of rats by inhibiting myocyte enlargement and brain natriuretic peptide (BNP) expression and hypertrophy markers, as well as the activation of AMP-activated protein kinase (AMPK) and eNOS signaling. Their study suggests that a $\mathrm{CB}_{1} / \mathrm{CB}_{2}$ dual cannabinoid agonist with low brain penetration could achieve cardioprotection and avoid undesirable central nervous system $\mathrm{CB}_{1}$ mediated effects. It is notable that protective effects caused by the endocannabinoid system highly involve the $\mathrm{CB}_{2}$ 
receptor activation. It is possible that new natural or synthetic compounds acting as an agonist of this receptor exhibit cardioprotective effects, leading to a decrease in the infarcted size/area, leukocyte-dependent damage of the infarcted myocardium, inhibition of superoxide species production, $\mathrm{Ca}^{2+}$ overload, or activation of relevant protective pathways, such as p38, ERK1/2, and STAT-3, thus minimizing heart damage.

\section{Bioavailability and Side Effects of CBD}

3.1. Pharmacokinetic Parameters of the Oral CBD Administration in Healthy Humans. As CBD is typically administered orally or by inhalation in humans, knowing the pharmacokinetics of $\mathrm{CBD}$ is important to establish therapeutic doses and treatment regimens for patients with mild or severe illness conditions. Taylor et al. [75] studied the pharmacokinetics of an orally administered, highly purified CBD pharmaceutical formulation in healthy patients. The study evaluated the effect of single and multiple administrations, as well as the effect of food on pharmacokinetic parameters. Four different doses $(1500,3000,4500$, and $6000 \mathrm{mg} /$ day) were administered in a single-dose trial. Maximal CBD concentration (Cmax) in plasma increased in a dose-dependent manner, but its time of maximal absorption (4-5 h) did not vary between the different doses. Similarly, the elimination half-time was similar for all doses (14$17 \mathrm{~h}$ ). Two different doses, 300 and $1500 \mathrm{mg}$ twice daily, were used in the multiple-dose trial. Maximal CBD concentrations were 1.6-fold higher than those in the single-dose trial, but time to maximal absorption was similar $(3 \mathrm{~h})$. Likewise, elimination half-times increased 4 -fold when compared to the single-dose trial, suggesting a degree of time dependency in the elimination of $\mathrm{CBD}$ upon multiple dosing. In the multiple-dose trial, there were no significant differences in elimination half-times with CBD doses, indicating a decrease in bioavailability due to solubility-limited absorption at higher doses. During the food effect trial, a fed state increased the Cmax of CBD when compared to the fasted state, resulting in a 4.85 -fold increase of the Cmax, demonstrating that the bioavailability of CBD increases with the food intake. As CBD is a highly lipophilic compound, a high-fat meal ingested at the time of dosing, which increases bile salt secretion and enhances absorption through hydrophobic barriers, may significantly increase the bioavailability of CBD, minimizing its loss. Additionally, as the formulation used in the study was not wholly pure, traces of THC may have been bioavailable. In all trials, THC, similar to the lower limit of quantification $(0.125 \mathrm{ng} / \mathrm{mL})$, was detected, demonstrating minimal interference of THC in CBD formulations.

3.2. Pharmacokinetic Parameters of the Oral CBD Administration in Humans with Impaired Conditions. It is crucial to establish the differences between healthy and ill patients' pharmacokinetics to establish proper treatment guidelines. For this purpose, Taylor et al. [76] studied the pharmacokinetics of a $200 \mathrm{mg}$ dose administered orally in patients with mild to severe hepatic impairment versus those with normal hepatic function. The Cmax of CBD increased with the severity of hepatic impairment, compared to the control group. However, there were no significant differences in the time of maximal absorption (2.0-2.8 h) between both groups. Similarly, elimination half-times increased with the severity of hepatic impairment by 1.83-, 2.39-, and 2.57-fold in patients with mild, moderate, and severe impairment, respectively, compared to the control group. The Cmax of 7-COOH-CBD, the most abundant CBD metabolite, decreased in patients with severe hepatic impairment due to a reduced metabolic capacity for hepatic biotransformation. Furthermore, although CBD highly bonds to proteins, mainly albumin, the free drug (not bonded to proteins) was notably higher in patients with severe hepatic impairment since baseline albumin levels were lower in these patients. In contrast, renal impairment [77] had no significant effect on the pharmacokinetics of CBD. Cmax, elimination halftime, and time to maximal absorption were not affected in patients with renal impairment when compared to the control group. CBD and its primary metabolites were not detected in the urine, suggesting this likely represents a minor route of elimination of the intact drug and its derivatives. Due to increased exposure to CBD, dose reduction is highly recommended in patients with moderate to severe hepatic impairment.

\subsection{Possible Side Effects of the CBD Oral Administration.} Regarding CBD's potential side/toxic effects, different studies involving the oral administration in healthy [65-74] or mentally ill [78-87] humans have been performed to measure safety-, behavioral-, or disease-specific parameters. Results have shown good tolerance and no significant adverse effects of $\mathrm{CBD}$ at a wide range of dosages, from 3 to $1,200 \mathrm{mg} /$ day. During the pharmacodynamic trials mentioned above [75-77], patients reported tolerance of all CBD oral administrations. The most common adverse effects reported were diarrhea, nausea, headache, and somnolence in healthy, hepatic-, and renal-impaired patients. Furthermore, there is no evidence that CBD has the potential for abuse or dependence in humans [88].

3.4. CBD Oral Bioavailability. CBD's oral bioavailability is poor, calculated at $8.6 \%$ compared to with the i.v. administration [89], and it is thought that $10 \%$ of the oral dose administered i.v. could exert similar effects. Due to the low oral bioavailability of $\mathrm{CBD}$, modifications of the pharmaceutical formulation must be considered to increase its effectiveness in patients. These modifications are focused on overcoming poor aqueous solubility and extensive first-pass metabolism. Knaub et al. [90] used a self-emulsifying drug delivery system (SEDDS-CBD), resulting in an up to 4.4 -fold increase in Cmax when compared to a commercial formulation. Similarly, Patrician et al. [91] reported an increase in Cmax with no differences in time to maximal absorption when using a modified oral CBD formulation. It is speculated that including long-chain fatty acids in the formulation could improve the uptake of $\mathrm{CBD}$, allowing higher volumes of CBD to enter the circulatory system. Furthermore, different Cmax values have been observed in women and men, with greater absorption in women than men $[90,92]$, probably due to differences in the distribution volume, women's higher percentage of 
body fat on average, or hormonal status, leading to higher exposure in women in a "one-size-fits-all" dosage strategy. In a study comparing various administration routes, Bartner et al. [93] assessed the pharmacokinetics of oral CBD-infused oil, microencapsulated CBD oil beads, and CBD-infused transdermal cream. The study demonstrated that CBDinfused oil had the most favorable pharmacokinetic profile since some diffusion barriers, such as skin thickness or absorptivity, compromise transdermal absorption.

The use of CBD as a therapeutic compound is gaining popularity, and the FDA has authorized its use in the treatment of different pathologies. However, the possibility of exerting adverse effects and the uncertainty that THC may exhibit its effects due to its content in CBD formulations limits its use. Despite the high dosages administered in the aforementioned studies, the possibility of CBD causing severe adverse effects is minimal, and diarrhea, nausea, headache, and somnolence are the most commonly reported sideeffects [75-77]. Unfortunately, CBD exhibits low bioavailability in oral administration, the current formulation approved by the FDA. Therefore, there is a considerable need for additional formulations with increased CBD bioavailability, as well as studies of the safety of using administration routes with increased bioavailability. Moreover, using therapeutic formulations composed of synthetic CBD could be an alternative, as no THC would be present, limiting concentration variations in the formulation, standardizing its effects, and potentially increasing its acceptance as a cardiovascular treatment.

\section{Clinical Trials Involving CBD and the Current State of CBD as a Treatment for Ventricular Dysfunction and Heart Failure}

The hallmark of cardiovascular diseases is a slow progression toward inflammatory pathologies. These are spurred by an unhealthy lifestyle, where smoking, high cholesterol, a diet rich in refined sugars, and high blood pressure lead to the endothelial activity [94]. Their clinical expressions include coronary artery disease, aortic aneurysms, peripheral artery disease, acute ischemic stroke, and venous thromboembolism [94].

Jadoon et al. [95] reported CBD's impact on blood pressure in healthy humans after an oral dose of $600 \mathrm{mg}$. In the study, the acute CBD administration reduced resting blood pressure and attenuated increases in blood pressure due to stressful situations. There are 247 clinical trials involving cannabidiol listed in the US National Library of Medicine database; most of them focus on pain relief and epilepsy, and four trials involve the measurement of cardiovascular parameters. An active study of oral dietary CBD supplements [96] in young and older healthy humans focuses on improving our understanding of how CBD might control and regulate blood vessel health, as well as cognitive and exercise performance, and includes systolic and diastolic blood pressure and heart rate measures. A completed study that assessed the effects of oral $\mathrm{CBD}(0,200,400$, or $800 \mathrm{mg} / \mathrm{Kg})$ on smoked marijuana's subjective, reinforcing, cognitive, and cardiovascular effects [97] evaluated the effect of CBD on the heart rate when smoking marijuana. The study showed an increase in heart rate $15 \mathrm{~min}$ after the inhalation of THC (5.3\%/cigarette), but it decreased over time, and no improvement was found in control participants $(0.01 \% \mathrm{TCH} /$ cigarette). They found no significant effects of CBD alone on the heart rate at every concentration. Another study aims at assessing the potential cardiovascular risks and benefits of CBD therapy in children with severe epilepsy [98] by characterizing CBD's effects on EKG findings, heart rate variability, and the occurrence of seizures. The measures include Holter SDNN parameter changes, seizure frequency, and dysautonomia signs and symptoms.

Regarding heart failure, experimental and clinical evidence supports the critical role of inflammation as the central mediator in the development and progression of heart failure [99]. B-cell activation signaling, which includes proinflammatory cytokines, anticardiac antibody expression, and complement system activation, directly correlates with functional class and outcomes [100, 101]. However, as previously described, when using in vivo and ex vivo preclinical cardiovascular models, CBD has shown a substantial protective effect from fibrosis and inflammation [102, 103]. Considering the link between inflammation and heart failure, CBD emerges as a promising, alternative anti-inflammatory therapeutic approach. Currently, from total clinical protocols related to the use of $\mathrm{CBD}$ in several diseases, just one treats with CBD patients with heart failure A-C (CAPITAL A-C, NCT03634189) [104]. In brief, CAPITAL-AC is a phase I, prospective, open-label study designed according to SPIRIT guidelines to assess the safety of cannabidiol treatment in patients with heart failure. The sample will include 20 patients with heart failure in stages $\mathrm{A}-\mathrm{C}$ (as defined by the American Heart Association/American College of Cardiology's guidelines) receiving guideline-directed medical therapy. The patients will receive cannabidiol at a maximum dose of $25 \mathrm{mg} / \mathrm{kg}$ daily with a follow-up of six months. The primary safety endpoints will be based on the incidence of adverse events. Additionally, high-sensitivity cardiac troponin $\mathrm{T}, \mathrm{B}$-type natriuretic peptide, tumor necrosis factor- $\alpha$, and immune and collagen biomarker testing and cardiac magnetic resonance imaging will be performed at the baseline, intermediate, and final visit. CAPITAL $\mathrm{A}-\mathrm{C}$, to the best of our knowledge, is the first phase I safety trial of cannabidiol in patients with heart failure in stages A-C [104]. However, this clinical trial is not complete, and the results are not available.

Notably, in the recent SARS-COV-2 pandemic, the most frequent COVID-19 phenotype is ST-elevation myocardial infarction, including males at high risk for thromboinflammation since they have proinflammatory risk factors and cardiopulmonary comorbidities [105]. The SARS-COV-2 infection leads to thromboinflammation, endothelial cell damage, increasing platelet aggregation, and thrombi sensitivity [106, 107]. The main targets of SARS-COV-2 are endothelial cells and pericytes on the lungs and myocardium, renal, arterial, and venous vessels, including venous and arterial microcirculation. This selectivity explains the most common clinical phenotypes observed in severe 
COVID-19. No vaccine is available for prevention, and there is no proven effective therapy for this infection. However, extensive preclinical data indicate that CBD has significant anti-inflammatory and cardioprotective effects. CBD interacts with a range of cellular receptors, which could potentially account for its anti-inflammatory activity. Considering these protective properties, CBD could prevent cardiovascular complications and, thus, improve patient care. In this regard, a recent study that evaluated CBD's efficacy and safety in patients with COVID-19 and cardiovascular disease or risk factors was reported as a clinical trial. The study, referred to as CRDL-COVID, is a doubleblind, placebo-controlled phase II-III study conducted to evaluate the effect of synthetic CBD on recovery in patients hospitalized due to COVID-19. The patients will receive cannabidiol in a maximum dose of $25 \mathrm{mg} / \mathrm{kg}$ daily with a follow-up of six months. The primary safety endpoints will be based on the incidence of adverse events. Additionally, high-sensitivity cardiac troponin T, B-type natriuretic peptide, enzyme elevation, and ECG abnormalities will be assessed as potential makers of efficacy. Then, the secondary endpoint regarding efficacy will include the percentage of patients whose COVID-19 infection requires intensive care, D-dimer elevation, the development of severe lymphopenia, and inflammatory markers. These current studies suggest that CBD is a compound with great potential to treat a variety of heart diseases. Moreover, the clinical evidence supporting its safety includes a notable lack of adverse effects. Results from the current protocol with patients who have cardiomyopathies could support the clinical use of CBD in cardiovascular diseases.

\section{Conclusion}

$\mathrm{CBD}$ is the most promising molecule in the family of cannabinoids, as several studies have pointed to its beneficial properties in the treatment of a wide number of diseases, including pain and anxiety control, neurodegenerative conditions, cardiovascular regulation, and perhaps, cancer. As it is derived mostly from botanical sources, a synthetic alternative is preferred because it can be obtained in a highly pure state, avoiding common contamination by undesired molecules derived from botanical purifications, such as THC, the main psychoactive compound found in cannabis [8]. CBD has been shown to have potent antioxidative effects, protecting cells from hypoxia, ischemia, and inflammatory processes. In the cardiovascular system, it can help to modulate vasorelaxation and myocardial contraction, and it is a promising therapy for chronic conditions, such heart failure, with few adverse effects or contraindications [11].

$\mathrm{CBD}$ has been administered to patients in a wide range of doses and found to be relatively safe. The literature suggests $\mathrm{CBD}$ is a compound with great potential to treat a variety of heart diseases, as animal models provide wide evidence of its cardiovascular effects, and early reports in humans evidence its low frequency of adverse effects. With the approval of different formulations of CBD by the FDA, clinical trials can be developed to ensure its efficacy in the treatment of cardiovascular diseases, including heart failure.

\section{Data Availability}

The data used to support the findings of this study are available from the corresponding author upon request.

\section{Conflicts of Interest}

The authors declare no conflict of interest.

\section{Authors' Contributions}

JA Garza Cervantes and M Ramos-González contributed equally to this work.

\section{Acknowledgments}

This work was partially supported by the Cardiovascular Medicine Research Group-Tecnológico de Monterrey 0020CAT131 as well as CONACYT-México grants 151136 and 256577 (G. García-Rivas).

\section{References}

[1] A. C. Campos, F. A. Moreira, F. V. Gomes, E. A. del Bel, and F. S. Guimarães, "Multiple mechanisms involved in the largespectrum therapeutic potential of cannabidiol in psychiatric disorders," Philosophical Transactions of the Royal Society B: Biological Sciences, vol. 367, no. 1607, pp. 3364-3378, 2012.

[2] W. A. Devane, F. A. Dysarz, M. R. Johnson, L. S. Melvin, and A. C. Howlett, "Determination and characterization of a cannabinoid receptor in rat brain," Molecular Pharmacology, vol. 34, no. 5, pp. 605-613, 1988.

[3] B. Horváth, P. Mukhopadhyay, G. Haskó, and P. Pacher, "The endocannabinoid system and plant-derived cannabinoids in diabetes and diabetic complications," The American Journal of Pathology, vol. 180, no. 2, pp. 432-442, 2012.

[4] M. R. H. Shayesteh, H. Haghi-Aminjan, M. J. Mousavi, S. Momtaz, and M. Abdollahi, "The protective mechanism of cannabidiol in cardiac injury: a systematic review of nonclinical studies," Current Pharmaceutical Design, vol. 25, no. 22, pp. 2499-2507, 2019.

[5] W.-S. Lee, K. Erdelyi, C. Matyas et al., "Cannabidiol limits T cell-mediated chronic autoimmune myocarditis: implications to autoimmune disorders and organ transplantation," Molecular Medicine, vol. 22, no. 1, pp. 136-146, 2016.

[6] O. Devinsky, M. R. Cilio, H. Cross et al., "Cannabidiol: pharmacology and potential therapeutic role in epilepsy and other neuropsychiatric disorders," Epilepsia, vol. 55, no. 6, pp. 791802, 2014.

[7] M. Mascal, N. Hafezi, D. Wang et al., "Synthetic, nonintoxicating 8,9-dihydrocannabidiol for the mitigation of seizures," Scientific Reports, vol. 9, no. 1, 2019.

[8] B. Jung, J. K. Lee, J. Kim et al., "Synthetic strategies for (-)-cannabidiol and its structural analogs," Chemistry - An Asian Journal, vol. 14, no. 21, pp. 3749-3762, 2019.

[9] WHO, Cardiovascular diseasesApr. 2020 https://www.who .int/health-topics/cardiovascular-diseases/\#tab=tab_1.

[10] G. Torre-Amione, S. Kapadia, J. Lee et al., "Tumor necrosis factor- $\alpha$ and tumor necrosis factor receptors in the failing human heart," Circulation, vol. 93, no. 4, pp. 704-711, 1996. 
[11] M. Rajesh, P. Mukhopadhyay, S. Bátkai et al., "Cannabidiol attenuates cardiac dysfunction, oxidative stress, fibrosis, and inflammatory and cell death signaling pathways in diabetic cardiomyopathy," Journal of the American College of Cardiology, vol. 56, no. 25, pp. 2115-2125, 2010.

[12] G. Solaini, A. Baracca, G. Lenaz, and G. Sgarbi, "Hypoxia and mitochondrial oxidative metabolism," Biochimica et Biophysica Acta - Bioenergetics, vol. 1797, no. 6-7, pp. 1171-1177, 2010.

[13] Y. Oropeza-Almazán, E. Vázquez-Garza, H. Chapoy-Villanueva, G. Torre-Amione, and G. García-Rivas, "Small interfering RNA targeting mitochondrial calcium uniporter improves cardiomyocyte cell viability in hypoxia/reoxygenation injury by reducing calcium overload," Oxidative Medicine and Cellular Longevity, vol. 2017, 13 pages, 2017.

[14] O. Lozano, A. Lázaro-Alfaro, C. Silva-Platas et al., "Nanoencapsulated quercetin improves cardioprotection during hypoxia-reoxygenation injury through preservation of mitochondrial function," Oxidative Medicine and Cellular Longevity, vol. 2019, 14 pages, 2019.

[15] R. P. Lifton, A. G. Gharavi, and D. S. Geller, "Molecular mechanisms of human hypertension," Cell, vol. 104, no. 4, pp. 545-556, 2001.

[16] A. C. Montezano and R. M. Touyz, "Molecular mechanisms of hypertension-reactive oxygen species and antioxidants: a basic science update for the clinician," Canadian Journal of Cardiology, vol. 28, no. 3, pp. 288-295, 2012.

[17] A. P. Landstrom, D. Dobrev, and X. H. T. Wehrens, "Calcium signaling and cardiac arrhythmias," Circulation Research, vol. 120, no. 12, pp. 1969-1993, 2017.

[18] M. Schwartz, S. Böckmann, and B. Hinz, "Up-regulation of heme oxygenase-1 expression and inhibition of diseaseassociated features by cannabidiol in vascular smooth muscle cells," Oncotarget, vol. 9, no. 77, pp. 34595-34616, 2018.

[19] C. P. Stanley, W. H. Hind, C. Tufarelli, and S. E. O'Sullivan, "Cannabidiol causes endothelium-dependent vasorelaxation of human mesenteric arteries via CB1activation," Cardiovascular Research, vol. 107, no. 4, pp. 568-578, 2015.

[20] M. Rajesh, P. Mukhopadhyay, S. Bátkai et al., "Cannabidiol attenuates high glucose-induced endothelial cell inflammatory response and barrier disruption," American Journal of Physiology-Heart and Circulatory Physiology, vol. 293, no. 1, pp. H610-H619, 2007.

[21] M. A. Fouda, M. R. Ghovanloo, and P. C. Ruben, "Cannabidiol protects against high glucose-induced oxidative stress and cytotoxicity in cardiac voltage-gated sodium channels," British Journal of Pharmacology, vol. 177, no. 13, pp. 29322946, 2020.

[22] R. M. Ali, L. T. Al Kury, K.-H. S. Yang et al., "Effects of cannabidiol on contractions and calcium signaling in rat ventricular myocytes," Cell Calcium, vol. 57, no. 4, pp. 290-299, 2015.

[23] O. J. Robertson-Gray, S. K. Walsh, E. Ryberg, A. C. JönssonRylander, C. Lipina, and C. L. Wainwright, "l- $\alpha$-Lysophosphatidylinositol (LPI) aggravates myocardial ischemia/reperfusion injury via a GPR55/ROCK-dependent pathway," Pharmacology Research \& Perspectives, vol. 7, no. 3, p. e00487, 2019.

[24] B. A. Marichal-Cancino, G. Manrique-Maldonado, A. H. Altamirano-Espinoza et al., "Analysis of anandamide- and lysophosphatidylinositol-induced inhibition of the vasopressor responses produced by sympathetic stimulation or noradrenaline in pithed rats," European Journal of Pharmacology, vol. 721, no. 1-3, pp. 168-177, 2013.

[25] C. P. Stanley, A. J. Wheal, M. D. Randall, and S. E. O'Sullivan, "Cannabinoids alter endothelial function in the Zucker rat model of type 2 diabetes," European Journal of Pharmacology, vol. 720, no. 1-3, pp. 376-382, 2013.

[26] A. J. Wheal, K. Jadoon, M. D. Randall, and S. E. O'Sullivan, "In vivo cannabidiol treatment improves endotheliumdependent vasorelaxation in mesenteric arteries of Zucker diabetic fatty rats," Frontiers in Pharmacology, vol. 8, 2017.

[27] S. E. O'Sullivan, Y. Sun, A. J. Bennett, M. D. Randall, and D. A. Kendall, "Time-dependent vascular actions of cannabidiol in the rat aorta," European Journal of Pharmacology, vol. 612, no. 1-3, pp. 61-68, 2009.

[28] P. Chiu, R. Karler, and C. Craven, "The influence of delta9-tetrahydrocannabinol, cannabinol and cannabidiol on tissue oxygen consumption," Research Communications in Chemical Pathology and Pharmacology, vol. 12, no. 2, pp. 267-286, 1975.

[29] P. Remiszewski, I. Jarocka-Karpowicz, M. Biernacki et al., "Chronic cannabidiol administration fails to diminish blood pressure in rats with primary and secondary hypertension despite its effects on cardiac and plasma endocannabinoid system, oxidative stress and lipid metabolism," International Journal of Molecular Sciences, vol. 21, no. 4, p. 1295, 2020.

[30] R. Kossakowski, E. Schlicker, M. Toczek, J. Weresa, and B. Malinowska, "Cannabidiol affects the bezold-jarisch reflex via TRPV1 and 5-HT3 receptors and has peripheral sympathomimetic effects in spontaneously hypertensive and normotensive rats," Frontiers in Pharmacology, vol. 10, 2019.

[31] R. Durst, H. Danenberg, R. Gallily et al., "Cannabidiol, a nonpsychoactiveCannabisconstituent, protects against myocardial ischemic reperfusion injury," American Journal of Physiology-Heart and Circulatory Physiology, vol. 293, no. 6, pp. H3602-H3607, 2007.

[32] Y. Feng, F. Chen, T. Yin et al., "Pharmacologic effects of cannabidiol on acute reperfused myocardial infarction in rabbits: Evaluated with 3.0t cardiac magnetic resonance imaging and histopathology," Journal of Cardiovascular Pharmacology, vol. 66, no. 4, pp. 354-363, 2015.

[33] S. K. Walsh, C. Y. Hepburn, K. A. Kane, and C. L. Wainwright, "Acute administration of cannabidiol in vivo suppresses ischaemia-induced cardiac arrhythmias and reduces infarct size when given at reperfusion," British Journal of Pharmacology, vol. 160, no. 5, pp. 1234-1242, 2010.

[34] E. Gonca and F. Darici, "The effect of Cannabidiol on ischemia/reperfusion-induced ventricular Arrhythmias," Journal of Cardiovascular Pharmacology and Therapeutics, vol. 20, no. 1, pp. 76-83, 2014.

[35] A. J. Wheal, M. Cipriano, C. J. Fowler, M. D. Randall, and S. E. O'Sullivan, "Cannabidiol improves vasorelaxation in Zucker diabetic fatty rats through cyclooxygenase activation," The Journal of Pharmacology and Experimental Therapeutics, vol. 351, no. 2, pp. 457-466, 2014.

[36] A. A. Fouad, W. H. Albuali, A. S. Al-Mulhim, and I. Jresat, "Cardioprotective effect of cannabidiol in rats exposed to doxorubicin toxicity," Environmental Toxicology and Pharmacology, vol. 36, no. 2, pp. 347-357, 2013.

[37] E. Hao, P. Mukhopadhyay, Z. Cao et al., "Cannabidiol protects against doxorubicin-induced cardiomyopathy by 
modulating mitochondrial function and biogenesis," Molecular Medicine, vol. 21, no. 1, pp. 38-45, 2015.

[38] L. B. M. Resstel, S. R. L. Joca, F. A. Moreira, F. M. A. Corrêa, and F. S. Guimarães, "Effects of cannabidiol and diazepam on behavioral and cardiovascular responses induced by contextual conditioned fear in rats," Behavioural Brain Research, vol. 172, no. 2, pp. 294-298, 2006.

[39] L. B. M. Resstel, R. F. Tavares, S. F. S. Lisboa, S. R. L. Joca, F. M. A. Corrêa, and F. S. Guimarães, "5-HT1Areceptors are involved in the cannabidiol-induced attenuation of behavioural and cardiovascular responses to acute restraint stress in rats," British Journal of Pharmacology, vol. 156, no. 1, pp. 181-188, 2009.

[40] F. V. Gomes, F. H. F. Alves, F. S. Guimarães, F. M. A. Correa, L. B. M. Resstel, and C. C. Crestani, "Cannabidiol administration into the bed nucleus of the stria terminalis alters cardiovascular responses induced by acute restraint stress through 5-HT1A receptor," European Neuropsychopharmacology, vol. 23, no. 9, pp. 1096-1104, 2013.

[41] É. M. Granjeiro, F. V. Gomes, F. S. Guimarães, F. M. A. Corrêa, and L. B. M. Resstel, "Effects of intracisternal administration of cannabidiol on the cardiovascular and behavioral responses to acute restraint stress," Pharmacology, Biochemistry, and Behavior, vol. 99, no. 4, pp. 743-748, 2011.

[42] Y. Liu, M. Jin, Y. Wang et al., "MCU-induced mitochondrial calcium uptake promotes mitochondrial biogenesis and colorectal cancer growth," Signal Transduction and Targeted Therapy, vol. 5, no. 1, 2020.

[43] M. Jenny, E. Santer, E. Pirich, H. Schennach, and D. Fuchs, " $\Delta 9$-Tetrahydrocannabinol and cannabidiol modulate mitogen-induced tryptophan degradation and neopterin formation in peripheral blood mononuclear cells in vitro," Journal of Neuroimmunology, vol. 207, no. 1-2, pp. 75-82, 2009.

[44] C. R. Hiley, "Endocannabinoids and the heart," Journal of Cardiovascular Pharmacology, vol. 53, no. 4, pp. 267-276, 2009.

[45] B. C. Willis, A. Salazar-Cantú, C. Silva-Platas et al., "Impaired oxidative metabolism and calcium mishandling underlie cardiac dysfunction in a rat model of post-acute isoproterenol-induced cardiomyopathy," American Journal of Physiology-Heart and Circulatory Physiology, vol. 308, no. 5, pp. H467-H477, 2015.

[46] E. Fernández-Sada, A. Torres-Quintanilla, C. Silva-Platas et al., "Proinflammatory cytokines are soluble mediators linked with ventricular arrhythmias and contractile dysfunction in a rat model of metabolic syndrome," Oxidative Medicine and Cellular Longevity, vol. 2017, 12 pages, 2017.

[47] H. Chapoy-Villanueva, C. Silva-Platas, A. K. GutiérrezRodríguez et al., "Changes in the stoichiometry of uniplex decrease mitochondrial calcium overload and contribute to tolerance of cardiac ischemia/reperfusion injury in hypothyroidism," Thyroid, vol. 29, no. 12, pp. 1755-1764, 2019.

[48] G. D. J. García-Rivas, K. Carvajal, F. Correa, and C. Zazueta, "Ru360, a specific mitochondrial calcium uptake inhibitor, improves cardiac post-ischaemic functional recovery in ratsin vivo," British Journal of Pharmacology, vol. 149, no. 7, pp. 829-837, 2006.

[49] Z. Jarai, J. A. Wagner, K. Varga et al., "Cannabinoid-induced mesenteric vasodilation through an endothelial site distinct from CB1 or CB2 receptors," Proceedings of the National
Academy of Sciences of the United States of America, vol. 96, no. 24, pp. 14136-14141, 1999.

[50] M. Joyeux, "Endocannabinoids Are Implicated in the Infarct Size-Reducing Effect Conferred by Heat Stress Preconditioning in Isolated Rat Hearts," Cardiovascular Research, vol. 55, no. 3, pp. 619-625, 2002.

[51] P. Lépicier, J. F. Bouchard, C. Lagneux, and D. Lamontagne, "Endocannabinoids Protect the Rat Isolated Heart against Ischaemia," British Journal of Pharmacology, vol. 139, no. 4, pp. 805-815, 2003.

[52] J. F. Bouchard, P. Lépicier, and D. Lamontagne, "Contribution of Endocannabinoids in the Endothelial Protection Afforded by Ischemic Preconditioning in the Isolated Rat Heart," Life Sciences, vol. 72, no. 16, pp. 1859-1870, 2003.

[53] N. J. Underdown, C. R. Hiley, and W. R. Ford, "Anandamide Reduces Infarct Size in Rat Isolated Hearts Subjected to Ischaemia-Reperfusion by a Novel Cannabinoid Mechanism," British Journal of Pharmacology, vol. 146, no. 6, pp. 809-816, 2005.

[54] A. Zakrzeska, E. Schlicker, M. Baranowska, H. Kozłowska, G. Kwolek, and B. Malinowska, "A Cannabinoid Receptor, Sensitive to O-1918, Is Involved in the Delayed Hypotension Induced by Anandamide in Anaesthetized Rats," British Journal of Pharmacology, vol. 160, no. 3, pp. 574-584, 2010.

[55] C. Di Filippo, F. Rossi, S. Rossi, and M. D’Amico, “Cannabinoid $\mathrm{CB} 2$ receptor activation reduces mouse myocardial ischemia-reperfusion injury: involvement of cytokine/chemokines and PMN," Journal of Leukocyte Biology, vol. 75, no. 3, pp. 453-459, 2004.

[56] F. Montecucco, S. Lenglet, V. Braunersreuther et al., "CB2 cannabinoid receptor activation is cardioprotective in a mouse model of ischemia/reperfusion," Journal of Molecular and Cellular Cardiology, vol. 46, no. 5, pp. 612-620, 2009.

[57] A. S. Gorbunov, L. N. Maslov, S. Y. Tsibulnikov et al., "CBReceptor agonist HU-210 mimics the postconditioning phenomenon of isolated heart," Bulletin of Experimental Biology and Medicine, vol. 162, no. 1, pp. 27-29, 2016.

[58] D. S. Ugdyzhekova, N. A. Bernatskaya, J. B. Stefano, V. F. Graier, S. W. Tam, and R. Mekhoulam, "Endogenous Cannabinoid Anandamide Increases Heart Resistance to Arrhythmogenic Effects of Epinephrine: Role of $\mathrm{CB}(1)$ and $\mathrm{CB}(2)$ Receptors," Bulletin of Experimental Biology and Medicine, vol. 131, no. 3, pp. 251-253, 2001.

[59] D. S. Ugdyzhekova, Y. G. Davydova, L. A. Maimeskulova, and R. Mechoulam, "Involvement of central and peripheral cannabinoid receptors in the regulation of heart resistance to arrhythmogenic effects of epinephrine," Bulletin of Experimental Biology and Medicine, vol. 130, no. 11, pp. 10871089, 2000.

[60] A. V. Krylatov, R. V. Uzhachenko, L. N. Maslov et al., "Endogenous Cannabinoids Improve Myocardial Resistance to Arrhythmogenic Effects of Coronary Occlusion and Reperfusion: A Possible Mechanism," Bulletin of Experimental Biology and Medicine, vol. 133, no. 2, pp. 122-124, 2002.

[61] A. V. Krylatov, R. V. Uzhachenko, L. N. Maslov et al., "Anandamide and R-(+)-methanandamide prevent development of ischemic and reperfusion arrhythmia in rats by stimulation of CB2-receptors," Eksp. Klin. Farmakol., vol. 65, no. 3, pp. 6-9, 2002.

[62] J. A. Wagner, K. Hu, J. Bauersachs et al., "Endogenous Cannabinoids Mediate Hypotension after Experimental 
Myocardial Infarction," Journal of the American College of Cardiology, vol. 38, no. 7, pp. 2048-2054, 2001.

[63] A. I. Matouk, A. Taye, M. A. El-Moselhy, G. H. Heeba, and A. A. Abdel-Rahman, "The effect of chronic activation of the novel endocannabinoid receptor GPR18 on myocardial function and blood pressure in conscious rats," Journal of Cardiovascular Pharmacology, vol. 69, no. 1, pp. 23-33, 2017.

[64] A. I. Matouk, A. Taye, M. A. El-Moselhy, G. H. Heeba, and A. A. Abdel-Rahman, "Abnormal cannabidiol confers cardioprotection in diabetic rats independent of glycemic control," European Journal of Pharmacology, vol. 820, pp. 256-264, 2018.

[65] L. Offertáler, F. M. Mo, S. Bátkai et al., "Selective ligands and cellular effectors of a $\mathrm{G}$ protein-coupled endothelial cannabinoid receptor," Molecular Pharmacology, vol. 63, no. 3, pp. 699-705, 2003.

[66] A. Penumarti and A. A. Abdel-Rahman, "The novel endocannabinoid receptor GPR18 is expressed in the rostral ventrolateral medulla and exerts tonic restraining influence on blood pressure," The Journal of Pharmacology and Experimental Therapeutics, vol. 349, no. 1, pp. 29-38, 2014.

[67] W.-S. V. Ho and C. R. Hiley, "Vasorelaxant activities of the putative endocannabinoid virodhamine in rat isolated small mesenteric artery," The Journal of Pharmacy and Pharmacology, vol. 56, no. 7, pp. 869-875, 2004.

[68] A. I. Bondarenko, O. Panasiuk, K. Drachuk, F. Montecucco, K. J. Brandt, and F. Mach, "The quest for endothelial atypical cannabinoid receptor: BKCa channels act as cellular sensors for cannabinoids in in vitro and in situ endothelial cells," Vascular Pharmacology, vol. 102, pp. 44-55, 2018.

[69] W. S. V. Ho and C. R. Hiley, "Vasodilator actions of abnormal-cannabidiol in rat isolated small mesenteric artery," British Journal of Pharmacology, vol. 138, no. 7, pp. 1320-1332, 2003.

[70] M. Baranowska-Kuczko, M. R. MacLean, H. Kozłowska, and B. Malinowska, "Endothelium-dependent mechanisms of the vasodilatory effect of the endocannabinoid, anandamide, in the rat pulmonary artery," Pharmacological Research, vol. 66, no. 3, pp. 251-259, 2012.

[71] J. Y. Su and A. C. Vo, "2-Arachidonylglyceryl ether and abnormal cannabidiol-induced vascular smooth muscle relaxation in rabbit pulmonary arteries via receptorpertussis toxin sensitive G proteins-ERK1/2 signaling," European Journal of Pharmacology, vol. 559, no. 2-3, pp. 189-195, 2007.

[72] G. Milman, Y. Maor, S. Abu-Lafi et al., "N-arachidonoyl Lserine, an endocannabinoid-like brain constituent with vasodilatory properties," Proceedings of the National Academy of Sciences of the United States of America, vol. 103, no. 7, pp. 2428-2433, 2006.

[73] S. Bátkai, P. Mukhopadhyay, J. Harvey-White, R. Kechrid, P. Pacher, and G. Kunos, "Endocannabinoids acting at CB1receptors mediate the cardiac contractile dysfunction in vivo in cirrhotic rats," American Journal of PhysiologyHeart and Circulatory Physiology, vol. 293, no. 3, pp. H1689-H1695, 2007.

[74] Y. Lu, B. C. Akinwumi, Z. Shao, and H. D. Anderson, "Ligand activation of cannabinoid receptors attenuates hypertrophy of neonatal rat cardiomyocytes," Journal of Cardiovascular Pharmacology, vol. 64, no. 5, pp. 420-430, 2014.

[75] L. Taylor, B. Gidal, G. Blakey, B. Tayo, and G. Morrison, “A phase I, randomized, double-blind, placebo-controlled, single ascending dose, multiple dose, and food effect trial of the safety, tolerability and pharmacokinetics of highly purified cannabidiol in healthy subjects," CNS Drugs, vol. 32, no. 11, pp. 1053-1067, 2018.

[76] L. Taylor, J. Crockett, B. Tayo, and G. Morrison, "A phase 1, open-label, parallel-group, single-dose trial of the pharmacokinetics and safety of cannabidiol (CBD) in subjects with mild to severe hepatic impairment," Journal of Clinical Pharmacology, vol. 59, no. 8, pp. 1110-1119, 2019.

[77] B. Tayo, L. Taylor, F. Sahebkar, and G. Morrison, "A Phase I, Open-Label, Parallel-Group, Single-Dose Trial of the Pharmacokinetics, Safety, and Tolerability of Cannabidiol in Subjects with Mild to Severe Renal Impairment," Clinical Pharmacokinetics, vol. 59, no. 6, pp. 747-755, 2020.

[78] P. Consroe, J. Laguna, J. Allender et al., "Controlled clinical trial of cannabidiol in Huntington's disease," Pharmacology, Biochemistry, and Behavior, vol. 40, no. 3, pp. 701-708, 1991.

[79] A. W. Zuardi, R. A. Cosme, F. G. Graeff, and F. S. Guimaraes, "Effects of ipsapirone and cannabidiol on human experimental anxiety," Journal of Psychopharmacology, vol. 7, 1_suppl, pp. 82-88, 2016.

[80] A. W. Zuardi, S. L. Morais, F. S. Guimaraes, and R. Mechoulam, "Antipsychotic effect of cannabidiol," Journal of Clinical Psychiatry, vol. 56, no. 10, pp. 485-486, 1995.

[81] A. W. Zuardi, J. E. C. Hallak, S. M. Dursun et al., "Cannabidiol monotherapy for treatment-resistant schizophrenia," Journal of Psychopharmacology, vol. 20, no. 5, pp. 683-686, 2006.

[82] F. M. Leweke, D. Koethe, C. W. Gerth et al., "Cannabidiol as an antipsychotic agent," European Psychiatry, vol. 22, p. S21, 2007.

[83] A. W. Zuardi, J. Crippa, J. E. C. Hallak et al., "Cannabidiol for the treatment of psychosis in Parkinson's disease," Journal of Psychopharmacology, vol. 23, no. 8, pp. 979-983, 2009.

[84] J. E. C. Hallak, J. P. Machado-de-Sousa, J. A. S. Crippa et al., "Performance of schizophrenic patients in the Stroop color word test and electrodermal responsiveness after acute administration of cannabidiol (CBD)," Revista Brasileira de Psiquiatria, vol. 32, no. 1, pp. 56-61, 2010.

[85] A. W. Zuardi, J. A. S. Crippa, S. M. Dursun et al., "Cannabidiol was ineffective for manic episode of bipolar affective disorder," Journal of Psychopharmacology, vol. 24, no. 1, pp. 135-137, 2008.

[86] J. A. S. Crippa, A. W. Zuardi, and J. E. C. Hallak, "Therapeutical use of the cannabinoids in psychiatry," Rev. Bras. Psiquiatr, vol. 32, 2010.

[87] J. A. S. Crippa, G. N. Derenusson, T. B. Ferrari et al., "Neural basis of anxiolytic effects of cannabidiol (CBD) in generalized social anxiety disorder: a preliminary report," Journal of Psychopharmacology, vol. 25, no. 1, pp. 121-130, 2010.

[88] G. Biosciences, EPIDIOLEX ${ }^{\circledR}$ (cannabidiol) oral solution, 2018, Jun 2020. https://www.accessdata.fda.gov/drugsatfda_ docs/label/2018/210365lbl.pdf.

[89] C. Xu, T. Chang, Y. Du, C. Yu, X. Tan, and X. Li, "Pharmacokinetics of oral and intravenous cannabidiol and its antidepressant-like effects in chronic mild stress mouse model," Environmental Toxicology and Pharmacology, vol. 70, article 103202, 2019.

[90] K. Knaub, T. Sartorius, T. Dharsono, R. Wacker, M. Wilhelm, and C. Schön, "A Novel Self-Emulsifying Drug Delivery System (SEDDS) Based on VESIsorb ${ }^{\circledR}$ Formulation Technology 
improving the oral bioavailability of Cannabidiol in healthy subjects," Molecules, vol. 24, no. 16, p. 2967, 2019.

[91] A. Patrician, M. Versic-Bratincevic, T. Mijacika et al., "Examination of a new delivery approach for oral cannabidiol in healthy subjects: a randomized, double-blinded, placebocontrolled pharmacokinetics study," Advances in Therapy, vol. 36, no. 11, pp. 3196-3210, 2019.

[92] T. Nadulski, F. Pragst, G. Weinberg et al., "Randomized, double-blind, placebo-controlled study about the effects of cannabidiol (CBD) on the pharmacokinetics of ??9Tetrahydrocannabinol (THC) after oral application of THC verses standardized cannabis extract," Therapeutic Drug Monitoring, vol. 27, no. 6, pp. 799-810, 2005.

[93] L. R. Bartner, S. McGrath, S. Rao, L. K. Hyatt, and L. A. Wittenburg, "Pharmacokinetics of cannabidiol administered by 3 delivery methods at 2 different dosages to healthy dogs," Canadian Journal of Veterinary Research, vol. 82, no. 3, pp. 178-183, 2018.

[94] W. C. Schrottmaier, M. Mussbacher, M. Salzmann, and A. Assinger, "Platelet-leukocyte interplay during vascular disease," Atherosclerosis, vol. 307, pp. 109-120, 2020.

[95] K. A. Jadoon, G. D. Tan, and S. E. O’Sullivan, “A single dose of cannabidiol reduces blood pressure in healthy volunteers in a randomized crossover study," JCI insight, vol. 2, no. 12, 2017.

[96] P. N. Ainslie, Cannabinoid Supplementation on Vascular and Cognitive Function, 2017, Jun. 2020. https://clinicaltrials.gov/ ct $2 /$ show $/ \mathrm{NCT} 03295903$ ? ter $\mathrm{m}=\mathrm{CBD}+\mathrm{Cannabidiol}$ + Epidiolex\&draw $=5 \&$ rank $=100$.

[97] National Institute on Drug Abuse (NIDA), Laboratory Study of Cannabidiol on the Effects of Smoked Marijuana, 2013, Jun. 2020 . ht t p s://clinicaltrials.gov/ct $2 / \mathrm{show} /$ NCT01844687?term $=C B D+C a n n a b i d i o l+E p i d i o l e x \&$ cond $=$ cardiovascular \&draw $=1 \&$ rank $=1$.

[98] G. C.'s. S. Healthcare, The Effects of Cannabidiol (CBD) on Electrical and Autonomic Cardiac Function in Children with Severe Epilepsy, 2016, Jun. 2020. https://clinicaltrials.gov/ ct2/show/NCT02815540?term $=\mathrm{CBD}+$ cannabidiol\&cond $=$ heart\&draw $=2 \&$ rank $=2$.

[99] L. Sánchez-Trujillo, E. Vázquez-Garza, E. C. Castillo, G. García-Rivas, and G. Torre-Amione, "Role of Adaptive Immunity in the Development and Progression of Heart Failure: New Evidence," Archives of Medical Research, vol. 48, no. 1, pp. 1-11, 2017.

[100] G. García-Rivas, E. C. Castillo, A. M. Gonzalez-Gil et al., “The role of B cells in heart failure and implications for future immunomodulatory treatment strategies," ESC Heart Failure, vol. 7, no. 4, pp. 1387-1399, 2020.

[101] E. C. Castillo, E. Vázquez-Garza, D. Yee-Trejo, G. GarcíaRivas, and G. Torre-Amione, "What is the role of the inflammation in the pathogenesis of heart failure?," Current Cardiology Reports, vol. 22, no. 11, 2020.

[102] C. P. Stanley, W. H. Hind, and S. E. O'Sullivan, "Is the cardiovascular system a therapeutic target for cannabidiol?," British Journal of Clinical Pharmacology, vol. 75, no. 2, pp. 313-322, 2013.

[103] C. Jerjes-Sánchez, Cannabidiol in Patients with Heart Failure Failure in AHA/ACC Stages A-C, 2018, Jun. 2020. https:// clinicaltrials.gov/ct $2 /$ show/NCT03634189? id = NCT03634189\&draw=2\&rank=1\&load=cart.
[104] T. Chen, D. Wu, H. Chen et al., "Clinical characteristics of 113 deceased patients with coronavirus disease 2019: retrospective study," BMJ, vol. 368, 2020.

[105] D. M. Musher, M. S. Abers, and V. F. Corrales-Medina, "Acute infection and myocardial infarction," The New England Journal of Medicine, vol. 380, no. 2, pp. 171-176, 2019.

[106] D. Atri, H. K. Siddiqi, J. P. Lang, V. Nauffal, D. A. Morrow, and E. A. Bohula, "COVID-19 for the cardiologist: basic virology, epidemiology, cardiac manifestations, and potential therapeutic strategies," JACC: Basic to Translational Science, vol. 5, no. 5, pp. 518-536, 2020.

[107] S. E. O'Sullivan, "An update on PPAR activation by cannabinoids," British Journal of Pharmacology, vol. 173, no. 12, pp. 1899-1910, 2016. 